\title{
The Arabs
}

\section{And the Achaemenid Invasion of Egypt ( 529-521 B.C ).}

Turhan Mazhar El Mufti

Iraq advisory council
Fadel Kazem Hanoun

Wasit University / College of Education for

تعد الامبراطورية الاخمينية (559 - 330ق.م ) إحدى أوسع الامبراطوريات مساحةً في التاريخ ، فقد امتدت

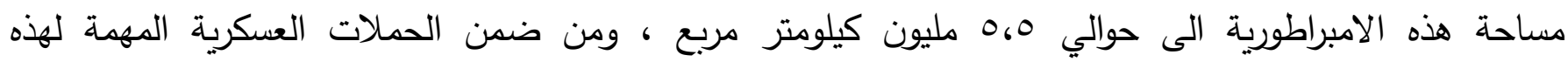

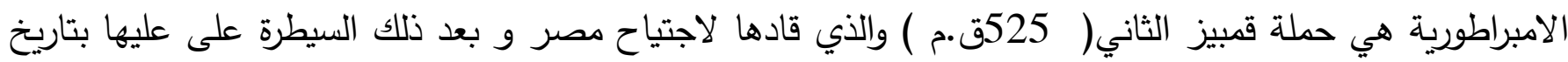

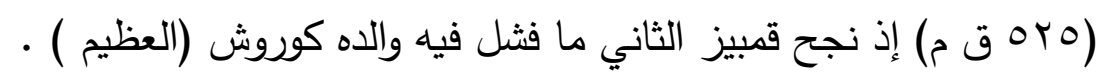

من الجدليات الواسعة لهذه الحملة هي كيفية اختراق جيش قمبيز للصحراء المثتدة بعد مدينة بابل غرباً وصولا الى مدفيس في مصر و السيطرة عليها ، وذلك من خلال مساعدة بعض القبائل أو الممالك العربية في أعالي أو شمال

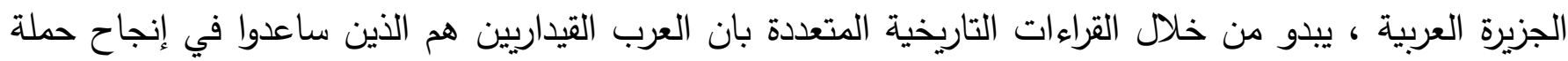

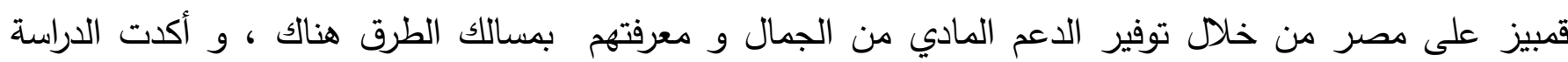

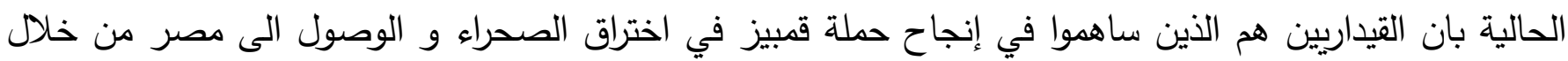

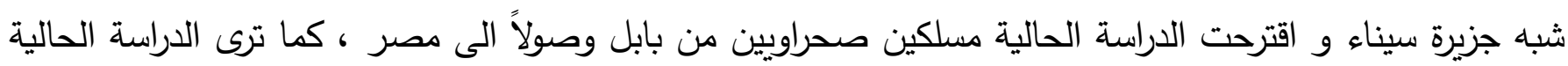
بان الثخصية أو الملك القيداري هو اياس بن مخلي والذي قدم المساعدة لهذه الحملة ، و ترجع سبب مساعدة

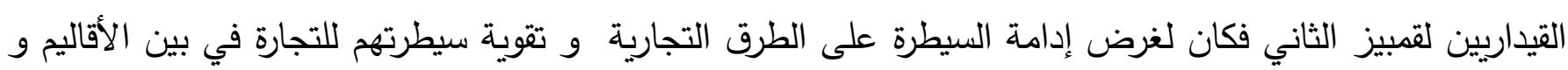
الممالك المختلفة في المنطقة. 
Abstract

The Achaemenid Empire ( 559-330 B.C) Is one of the largest empires in the long of the history. The area which controlled by this empire extended to about 5.5 million square kilometers, Among of many of military campaigns of this empire it was the campaign to control Egypt, which done by Cambyses II (525B.C) And that which followed to invade Egypt after that, that was accomplished on a date (525 BC .), Where Cambyses II succeeded in what Cyrus (the great) failed One of the most discussed topics in this campaign it was about how the Cambyses army penetrated the desert extending beyond the city of Babylon in the west to Memphis in Egypt and controlled it, through the help of some Arab tribes or kingdoms in the upper or northern Arabian Peninsula. They are the ones who helped in the success of the Cambyses campaign in Egypt by providing financial support from camels and their knowledge of the road routes there..

The current study confirmed that the Qaidarians were the ones who contributed to the success of the Cambyses campaign in penetrating the desert and reaching Egypt through the Sinai Peninsula. The current study suggested two desert paths from Babylon to Egypt, the name of the Arabian king (Qaidarian) which provided assistance to this campaign was Eyas bin Muchli, and the reason for the Qaidarians whose helped is attributed to Qambiz II was for the purpose of maintaining control over trade routes and strengthening their control of trade between the various regions and kingdoms in the region.. 
شغلت حملة الملك الأخميني قمبيز الثاني (529-521 ق.م) التي قادها للسيطرة على مصر عام 525 ق.م المؤرخين والآثاريين على حد سواء إذ تعددت الآراء في معرفة من القبائل العببية التي ساعدت قمبيز على اجتياز

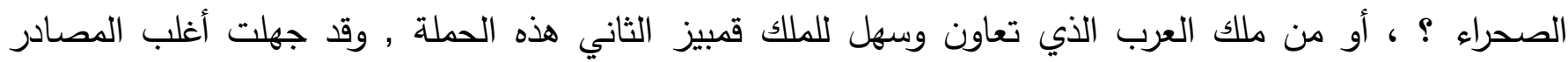
معرفته ! والتي ذكرت بأن العرب هم من تعاونوا مع قمبيز الثاني . شمل هذا البحث أربعة محاور : الدحور الأول: تضمن دراسة تولي قمبيز الثاني السلطة 529 ق.م من بعد والده كوش الذي اختاره وليا للعهد من

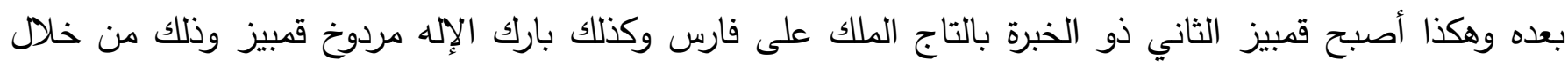

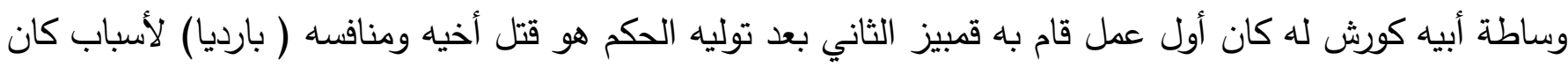

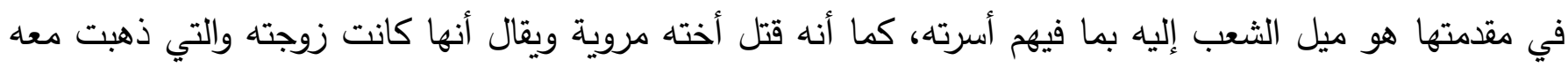
إلى مصر.

في حين تضمن المحور الثاني: دراسة الإستراتيجية الإدارية العسكرية للدولة الاخمينية في عهد قمبيز الثاني(529-

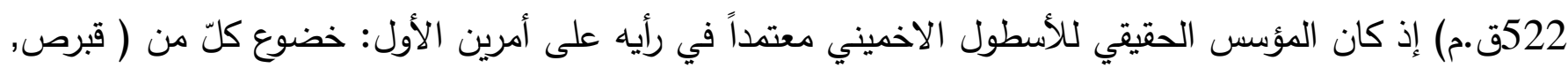

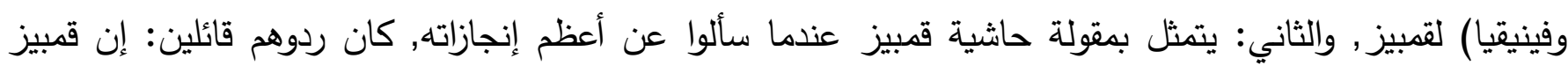

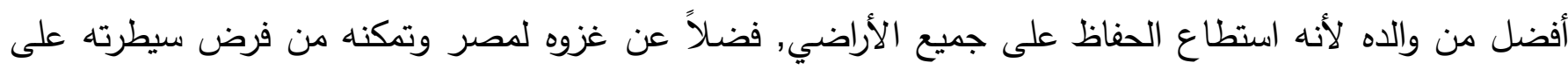

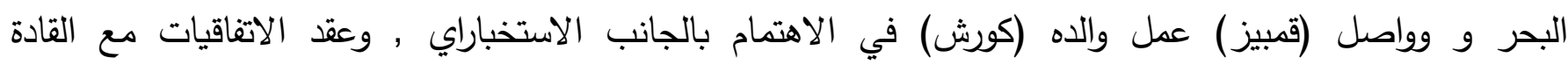

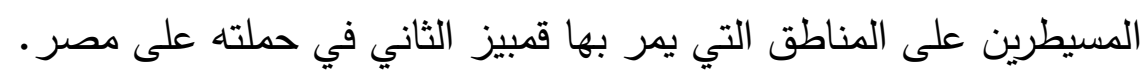

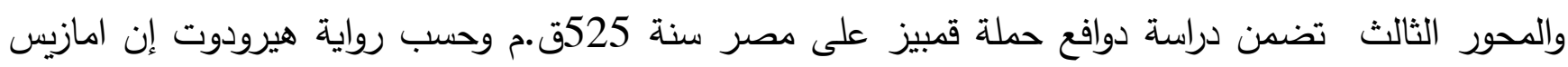

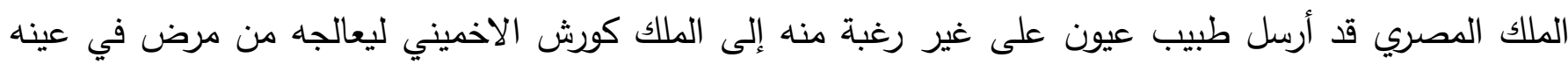

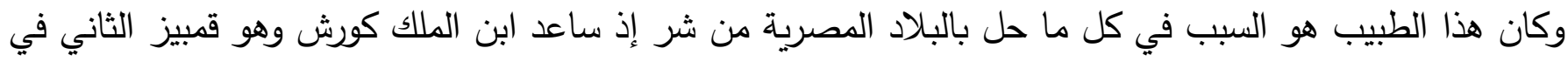

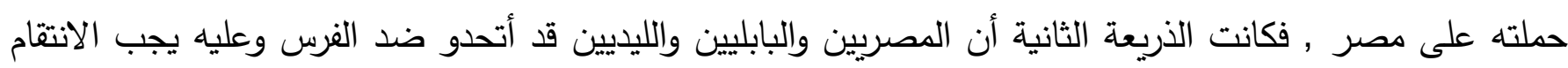
منهم إلا إن هدف الحملة الحصول على المزيد من الأراضي الثرية والكثيرة الخيرات ومن اجل توسيع رقعة ولئ الإمبراطورية.

كما تضمن المحور الرابع: تضمن دراسة الحملة والطرق التي سلكها قمبيز والقبائل العربية التي ساعدته وأثبتت

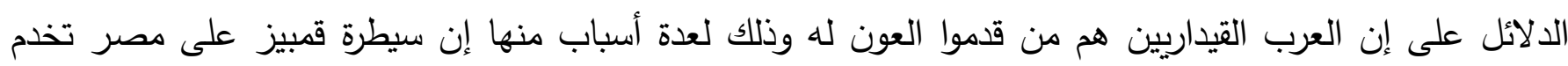

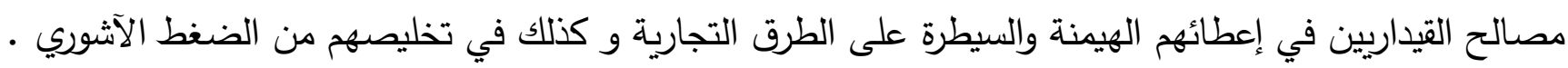


ختم البحث باستتناجات توصلنا إليها نصت على أن الآراء تعددت حول العرب الذين ساعدوا الملك الاخميني قمبيز

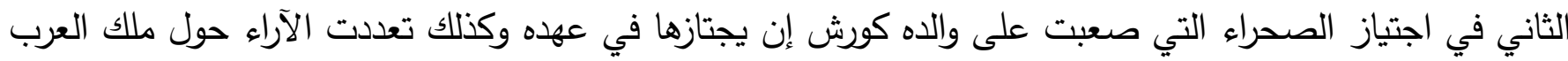

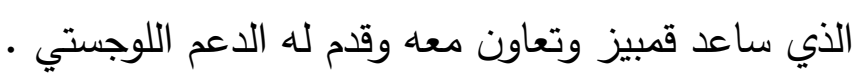

تولي الملك قمبيز الثاني العرش الأخميني سنة 529 ق.م وهو الابن الأكبر للملك الأخميني كورش الثاني (1)(558-530ق.م). وأمه كاساندان ابنة فرناسب التي توفيت قبل زوجها كورش الثاني وأثرت فيه كثيراً إذ حزن الإن

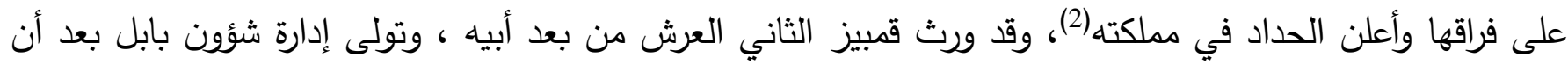

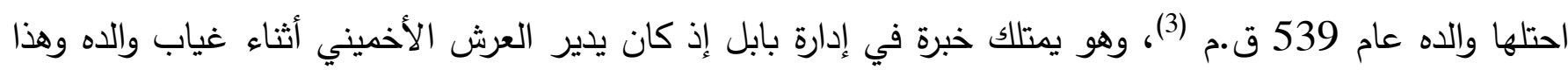
ساعده في تسلم العرش من بعد أبيه كونه ذو خبرة في الحكم , كما استمد الثرعية في حكم بابل أيضا من التصريح

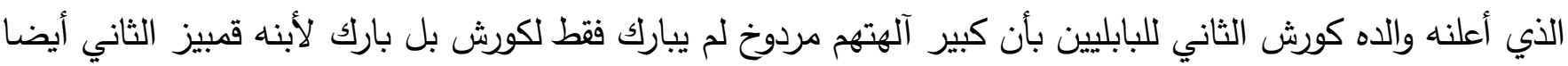

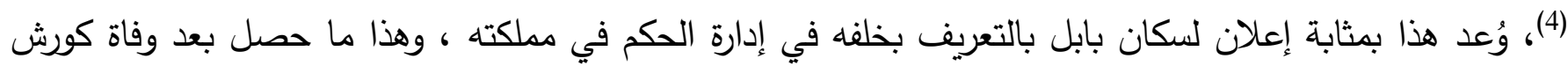

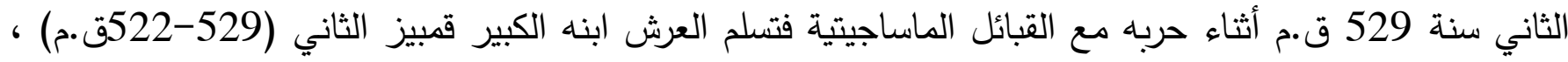
وعند تسلمه الحكم واجهته بعض المشاكل إذ ثارت الولايات التي فتحها من قبل والده لكنه تمكن من إخماد ثوراتهم التهاء

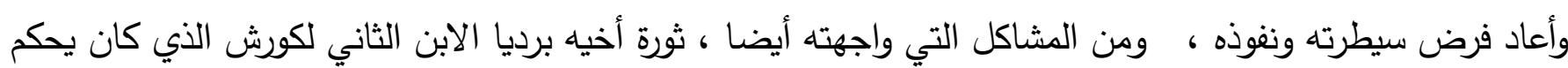

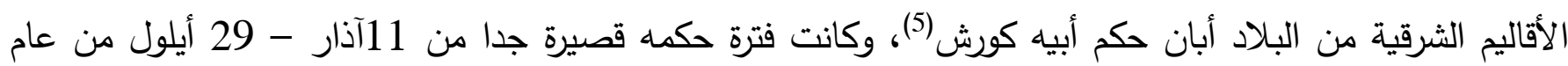

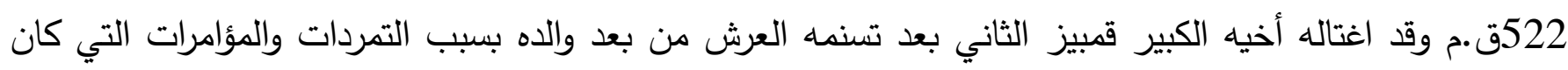

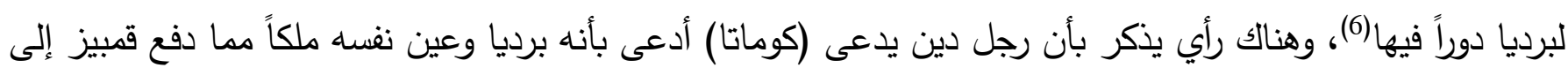

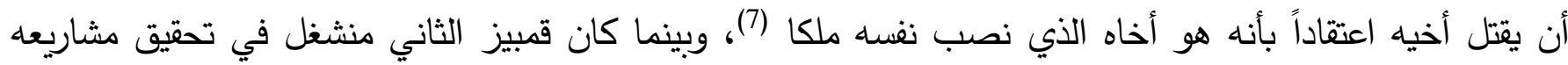

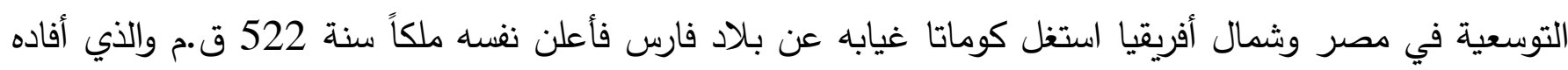

() Olmsted, History of the Persian Empire,Chicago.1984 . ${ }^{1}$ 2 ()شرين بياني , تاريخ ايران باستان , ج2, ص 107. 3 ()المصدر نفسه , ص273.

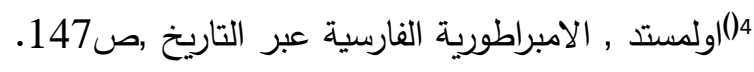

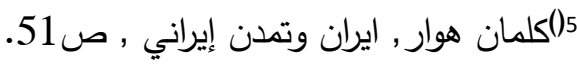

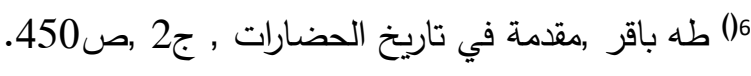

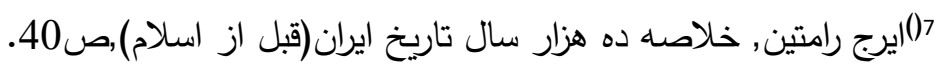


بذلك هو الثبه بينه وبين برديا الابن الثاني لكورش الثاني الذي قتله قبيز وأخفى ذلك عن الناس ولم يستطيع أن يعلن

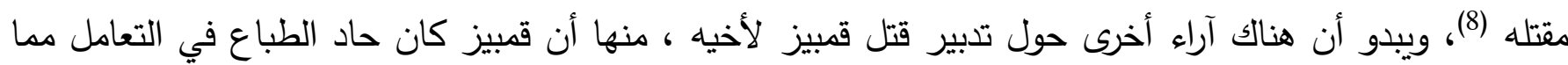
أدى إلى ميل الثعب لأخيه الأصغر بارديا إذ كان على العكس من أخيه قمبيز الثاني لطيفاً و متواضع فأنضم بارديا

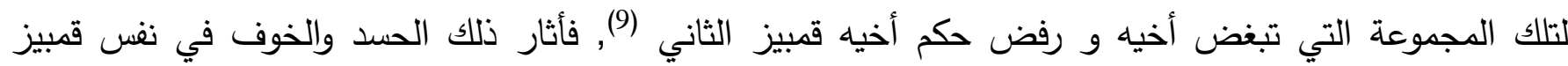

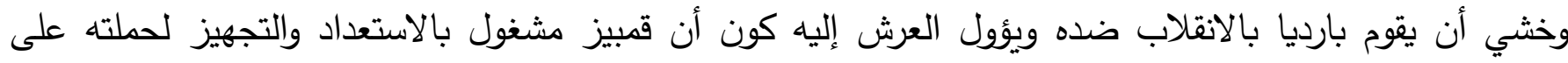

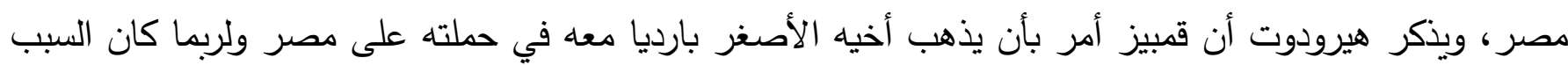

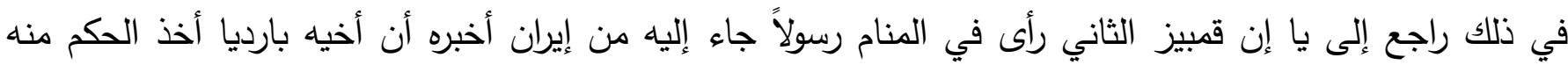

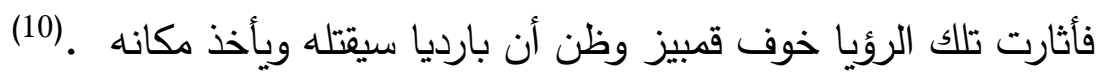

تعددت الروايات في مقتل بارديا إذ تذكر أحداها أن قمبيز الثاني أمر رجل معروف من وجهاء فارس أسمه

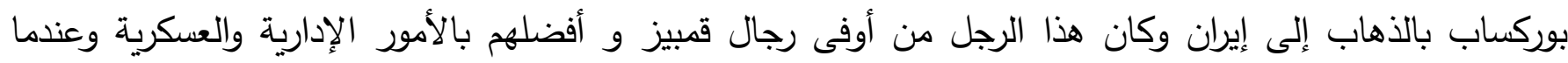

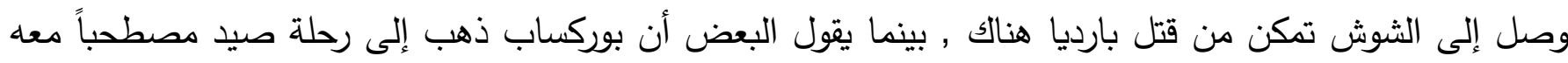

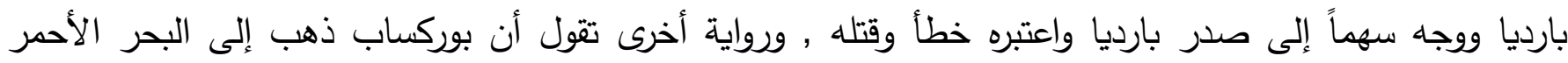

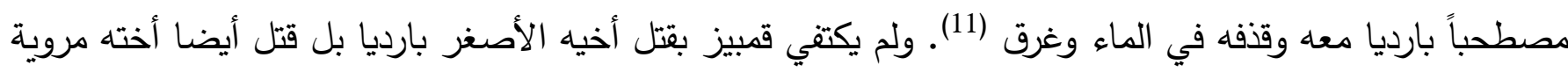
والتي ذكرتها بعض الدصادر على أنها زوجته وأن سبب مقتلها حسب ما تذكره الروايات هو الهدية التي قدمت لقدئ لقبيز

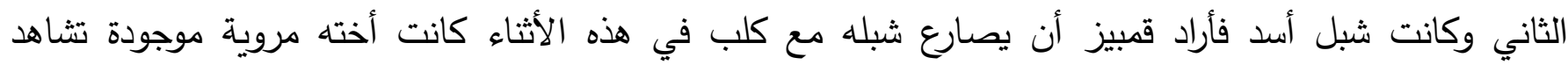

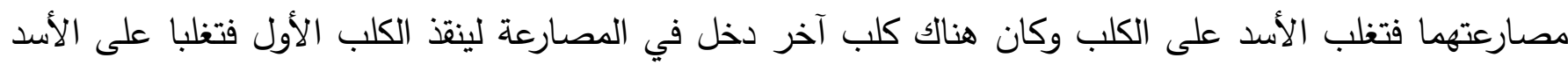

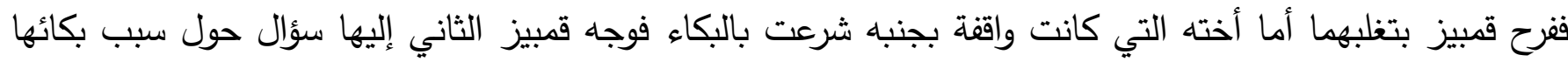

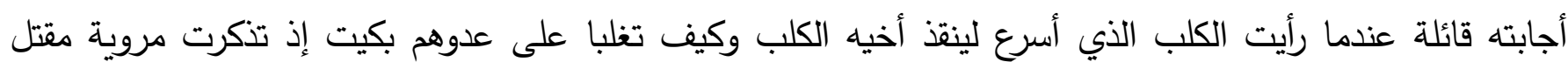
أخيها بارديا الذي لا يستطيع أحد أخذ ثأره (12)، حسب اعتبان لأنقاد هيرودوت.

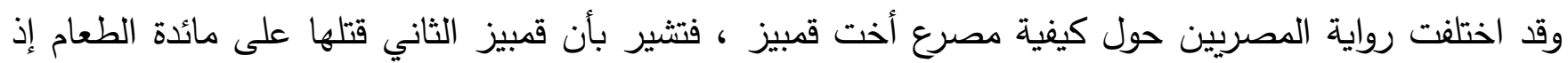

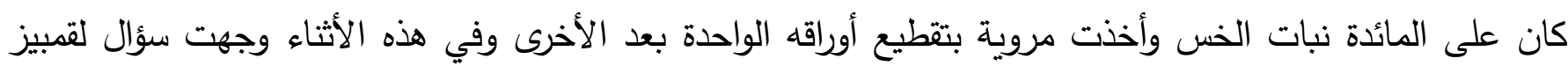

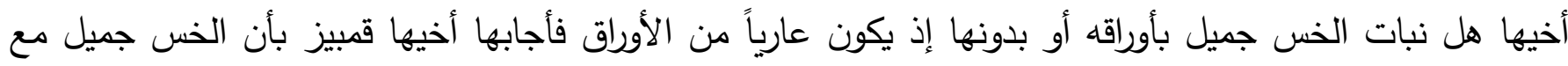

8) حسن بيرنيا, تاريخ ايران باستان امبراطوري هخامنشيان كورش قمبيز الثاني دارا الأول خشيارشا,ص90-91.91.

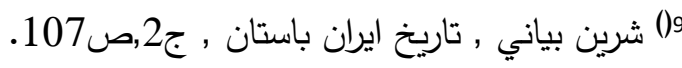

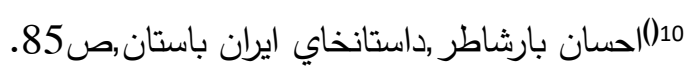

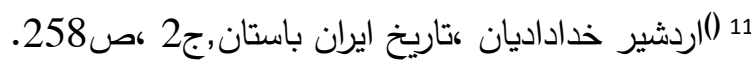

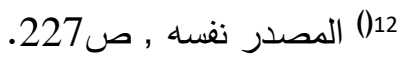


أوراقه فردت عليه قائلة أنما أن ما قمت به يا قمبيز يشبه الذي قطع أوراق الخس وجعل ساقه عارية فأنت جعلت أسرة

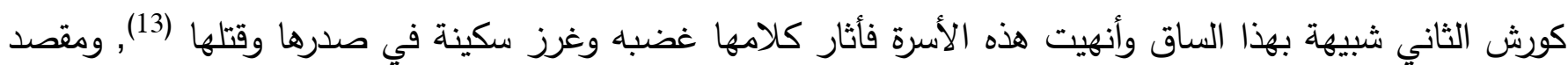
كلامها بذلك هو أن العرش سيأخذ من عائلة كورش الثاني بعد مقتل بارديا وهذا ما حصل فأخذ الحكم من بعد قمبيز الملك دارا الأول (521-486ق.م) بعد أن استطاع القضاء على فتتة كوماتا الذي انتحل شخصية بارديا شقيق قمبيز

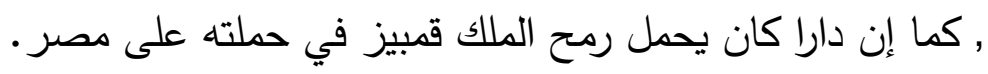
المحور الثاني: nan الإستراتيجية الإدارية العسكربة للدولة الاخمينية في عهد قمبيز الثاني(529-522ق.م).

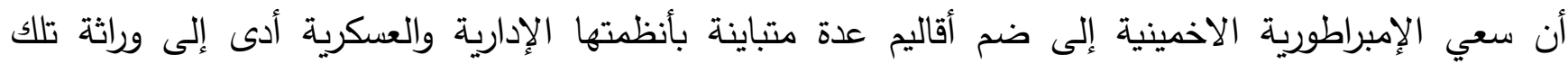

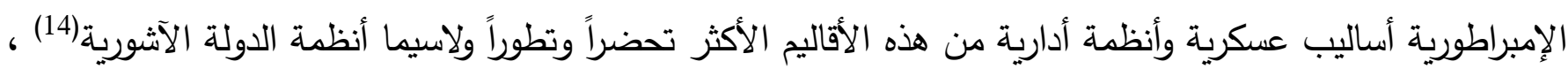

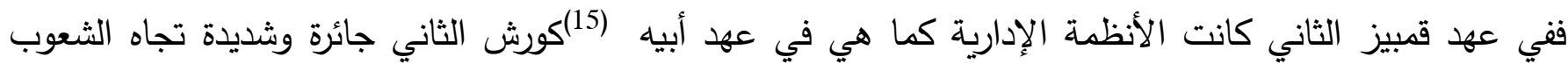
الخاضعة لسلطتهم فليس لهم حق في الاعتراض على تصرفات الأخمينين , وبمكن ملاحظة استخدم الأخمينين

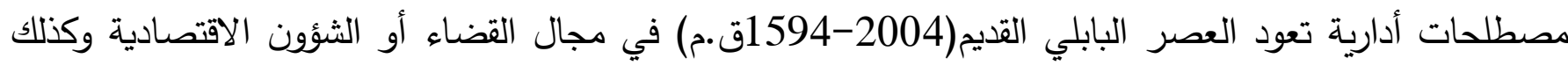
مصطلحات أكدية وردت في بعض نصوص العصر الآشوري الحديث (911-612ق.م) وعدت من أهم الوظائف الإدارية. (16) (16)

أما انجازات الملك قمبيز الثاني العسكرية هو تأسيس القوة البحرية الإيرانية حيث صرف أموال كثيرة في استثمار

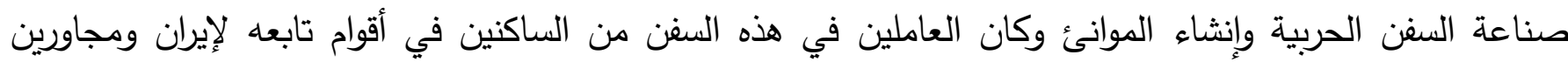

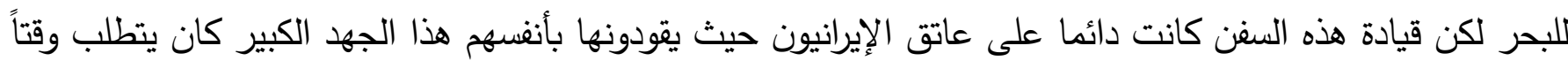

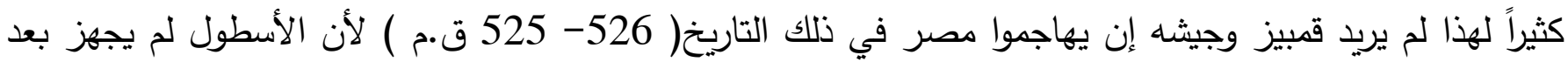

(13 (13 المصدر نفسه , ص227.

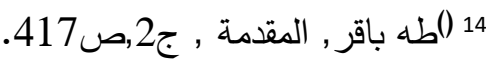

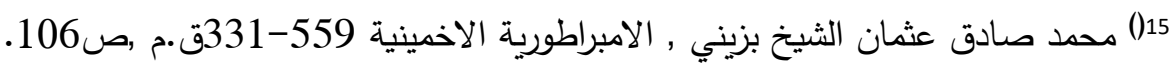
: (16 اللمزيد ينظر صنان : (16)

R.J. van der Spek, Cyrus the Great, Exiles and Foreign Gods - A Comparison of Assyrian and Persian Policies on Subject Nations, "Cyrus de Pers in Assyrisch perspectief: Een vergelijking tussen de Assyrische en Perzische politiek ten opzichte van onderworpen volken, (VU University Amsterdam, 
(17), كما إن قمبيز جعل ميناء (غزة) مركز لحركات السفن الفينيقية والقبرصية التي سبق وان أعلنت خضوعها له , وعقد معاهدات مع زعماء القبائل العربية التي كانت تقطن طريق حملته على مصر واستأجر الإبل منهم مقابل إعفائهم من دفع الجزية السنويـة التي فرضتها عليهم الدولة الأخمينية وعلى جميع الولايات التابعة لها (18)، وعد قمبيز الثاني أفضل من والده وفق مقولة حاشيته عندما سُألوا عن أعظم انجازاته إذ ردوا قائلين " أن قمبيز أفضل من والده لأنه استطاع الحفاظ على جميع الأراضي " فضلا عن غزوه لمصر وتمكنه من فرض سيطرته على البحر (19). ولم يكن قمبيز مهتم فقط بالجانب الحربي بل له اهتمام بالجانب الاستخباراتي إذ واصل عمل والده كوش فقبل غزوه مصر حصل على معلومات مهمه عن أحوال البلاد عن طريق طبيب مصري يقيم في إيران, وأيضا أرسل سفراء إلى ملك الحبشة بحجة تقديم الهدايا ولكن ملك الحبشة علم بغايتهم وهي التجس فأجابهم بصراحة تامة بأن ملكهم أرسلهم بهذه الهدايا ليس من اجل الصداقة والهدف من مجئهم هو التجس على بلاده (20). و كان لقمبيز أيضا خبرة عسكرية بارعة ، فمن ضمن خبرته هو تخطيطه الذكي لتسهيل السيطرة على عدوه ، وهذا التكتيك قد استعمله أبان التمهيد لاحتلال مصر فقد قطع الإمدادات عن المصريين عام 522 ق.م ، كما قطع عليهم الطرق التي من خلالها تصل المؤونة والإمدادات للجيش المصري ومن الخبرات العسكرية التي يتمتع بها قمبيز الثاني أيضا هي نشر سياسة التقرقة بين خصومه ، وتجريد الملك من حلفائه وهذا ما طبقه على الملك المصري أحمس الثاني عندما قرر قمبيز الثاني مهاجمة مصر • (21) : المحور الثالث دوافع حملة قمبيز على مصر سنة 525 ق.م .

تعددت الآراء حول أسباب حملة الملك الأخميني قمبيز الثاني على مصر سنة 525 ق .م وفي مقدمة الأسباب أن ذهاب قمبيز الثاني إلى مصر كان مخطط له منذ عهد أبيه كور الثاني الذي وقفت الصحراء عائق بوجهه وأن كوش الثاني هو الذي أمر أبنه قمبيز الثاني بالتوجه إلى مصر (22) , أما الرأي الآخر كما يذكره هيرودوت أن الملك

$$
17 \text { ()آملي كورت , هخامنشيان, ص47. }
$$

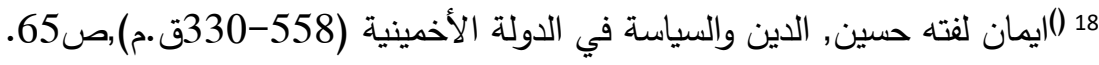

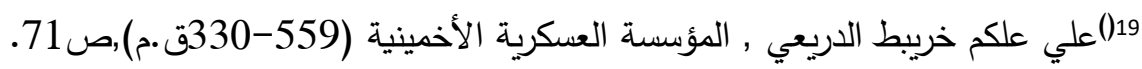
20((المصدر نفسه , ص206. 21(1)المصدر نفسه , ص ص270 272-272 .

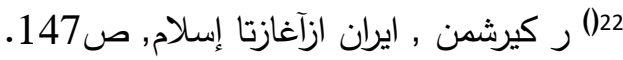




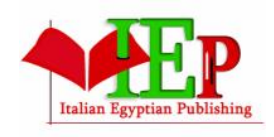

ISSN: 2735-4393
INTERNATIONAL JOURNAL OF

CREATIVITY AND INNOVATION IN HUMANITIES AND

EDUCATION

VOLUME 4, ISSUE 1, 2021, $24-47$.

$\overline{\vdots: \vdots\left(\begin{array}{c}\text { ISTITUTO } \\ \text { italiano } \\ \text { DI CULTURA }\end{array}\right.}$

www.egyptfuture.org/ojs/

المصري أمازيس (أحمس الثاني) قد أجبر طبيب عيون على الذهاب إلى بلاد فارس لمعالجة الملك كوش الثاني من مرض في عينه والعمل في بلاد الفرس الأخمينيين وكان هو السبب لما حصل لمصر (23), إذ أقترح على الملك قمبيز الثاني أن يتزوج من بنت الملك المصري أمازيس ويبدوا إن هذا الجراء سبب إحراجا لأمازيس لأنه لا يريد الموافقة وبنفس الوقت تخوف من الرفض لأنه سيجلب لنفسه كراهية قمبيز له وكان امازي يخشى قوة الفرس وأيضا توقع بأن ابنته لم تكن زوجة رسمية لقمبيز الثاني بل سيجعلها محظية لهذا قام امازيس ببعث بنت أخرى بدل ابنته كانت هي الوحيدة الناجية من عائلتها التي قتلهم الملك المصري امازيس اسمها (نتيس) ابنة الملك السابق أبريس فزينها امازيس بالملابس والذهب وأرسلها إلى بلاد فارس على أنها ابنته التي طلب يدها قمبيز الثاني(24). بعد أن تزوجت نتيس ابنة الملك السابق لمصر أبريس من قمبيز الثاني الذي كان يظنها ابنة الملك امازيس الذي لبى طلبه ناداها في احد الأيام يا ابنة امازيس فانتهزت الفرصة وقالت لقمبيز أني لست من تظن وأن الملك امازيس خدعك فقد كساني بأجمل الثياب وأفخرها وزينني بأنفس الحلي كأنني أبنته لكن في الحقيقة أن ابنة الملك أبريس رئيسه وسيده إلا إن امازيس قتله وسلب

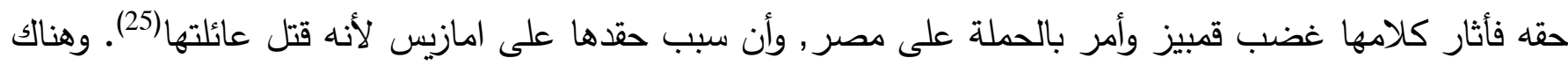
رأي آخر لا يرجحه هيرودوت وهو إن الحملة على مصر كانت استرجاع للعرش المغتصب إذ أن قمبيز الثاني هو ابن كوش من ابنة أبريس , وبطلب قمبيز الثاني ليد ابنة الملك امازيس مخالف للعادات الفرس في توليه الحكم لأنه الذي يتولى العرش يجب أن يكون والديه أخمينيين وهذا ما يعرفه المصريين , وان كان هذا الكلام صحيح فمتى تم زواجهج؟ إذ أن مصر كانت في المعسكر المضاد للفرس أثناء حروب أبيه كور الثاني كذلك كم كان عمر قمبيز؟ عندما حكم بابل, فضلا عن إن قمبيز الثاني من عائلة كيانية وليست مصرية إذ أن أمه كسندانة بنت فرناسب(26) ـ أما الرأي الآخر إن احد نساء كوش مدحتها امرأة في بلاطه واثثت عليها بكل جميل مدا أثار شك الملكة أم قمبيز الثاني حول كورش زوجها وكذلك بسبب مبالغته أيضا في الثناء على نفس المرأة التي هي من ضمن من نسائه وكانت مصرية فغضب قمبيز لذلك فأسرها في نفسه وقال لأمه انه سيجعل عالي مصر سافلها(27) , بسبب ذلك وكان في وقتها بسن العاشرة , وهنالك رأي آخر يشابه الرأي السابق إلا انه خالي من الصحة كما قال عنه هيرودوت وهو إن سبب احتلال قبيز لمصر كان تنفيذا لوعد قطعه لوالدته بعد أن سمعت إطراء بحق أولادها من إحدى الوجيهات في البلاط الاخميني والتي أجابتها عليه إن مع هذه الصفات التي يتمتع بها أولادها إلا إن كوش يفضل عليها امرأة مصرية(28) ـ مهما

$$
\text { 2323(0ليم حسن,مصر القديمة,ج13, ص36. }
$$$$
25 \text { () المصدر نفسه , ص21 } 21 \text { (1) }
$$

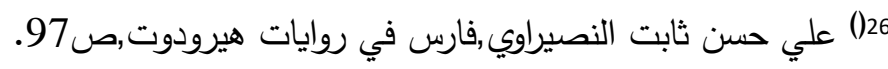

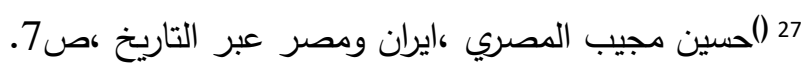

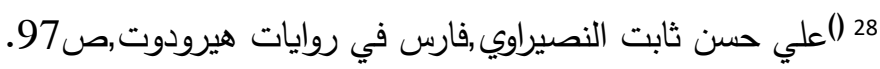


تعددت الأسباب فأن مشروع مصر مخطط له من قبل استلام قمبيز الثاني للعرش أي منذ حكم أبيه كورش وان وفاة

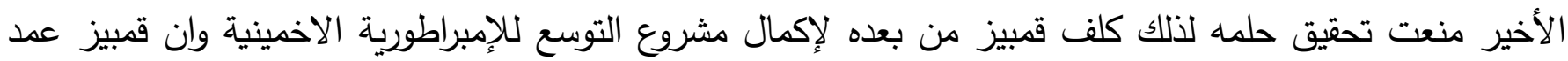

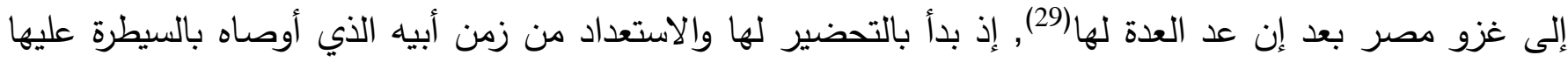

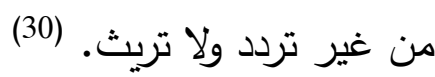

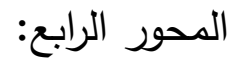

سير الحملة ودور العرب في مساعدة الملك قمبيز الثاني باجتياز الصحراء

بعد أن قرر قمبيز احتلال مصر أخذ يدبر الخطط من أجل حملته , وكان فرعون مصر امازيس يتوقع هجوم

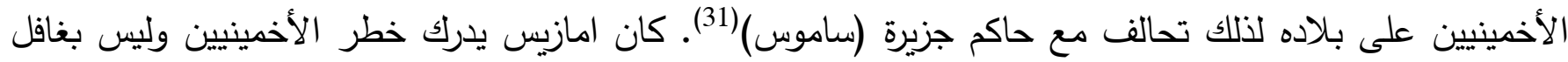

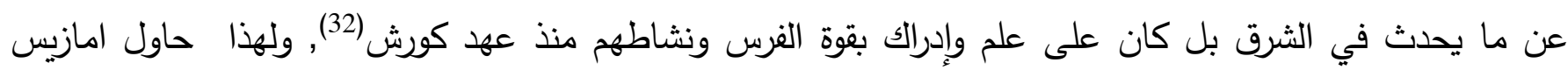
التقرب من سكان قورنيائية وطلب مساعدة معبد دلفي و رودرس بت بتقديم الكتان الموشى بالذهب وأعطى قمبيز معبد

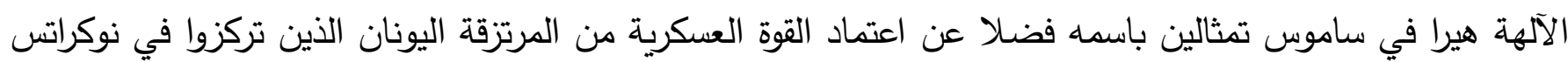
بالجزء الغربي من الدلتا منذ القرن السابع قبل الميلاد, فقد كان يتمتع امازيس بعلاقة وطيدة مع الئه اليونانيين وهذا ما ذكره

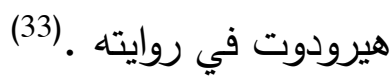

بدأ قمبيز الثاني يعد العدة من اجل انطلاق حملته إلى مصر إذ بدأ بتجريد الفرعون المصري امازيس من حلفائه

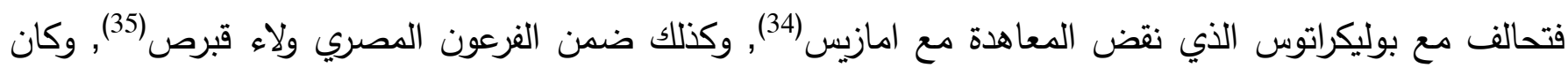

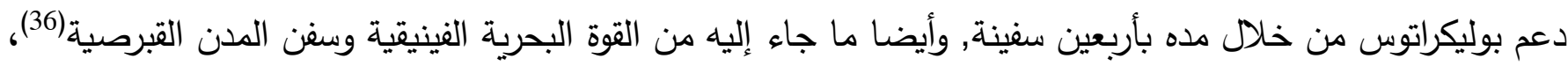
إن الظروف التي مرت بها جزيرة ساموس ساعدت قمبيز الثاني في إتمام حملته على بلاد مصر فكانت إسبارطة

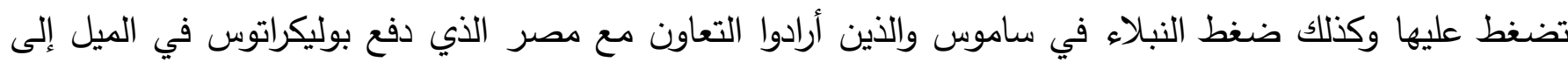

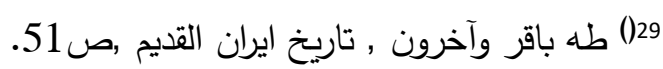

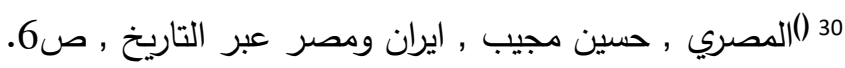

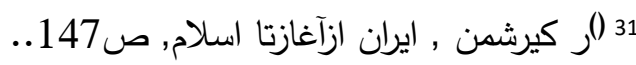

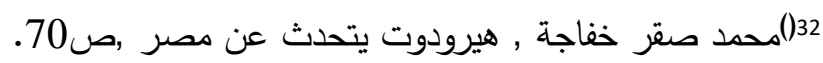

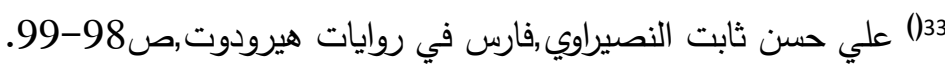

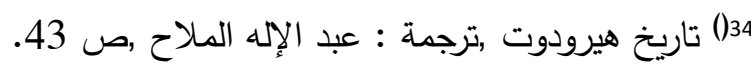

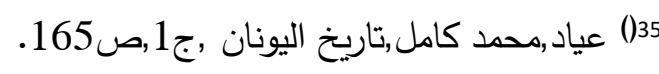

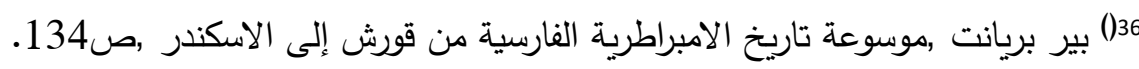




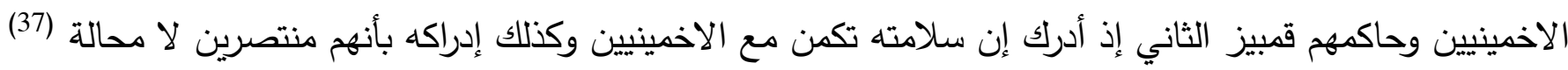

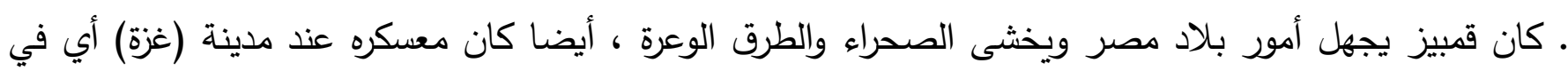

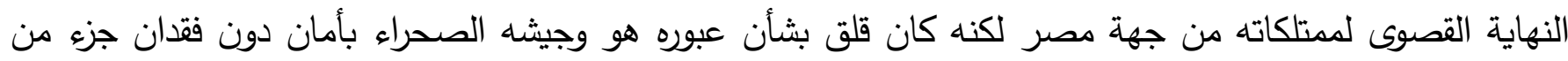

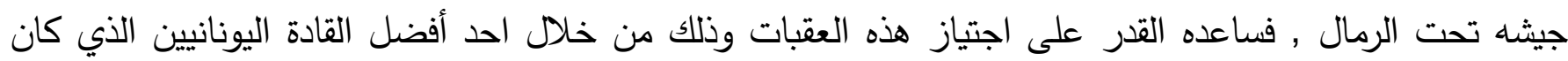

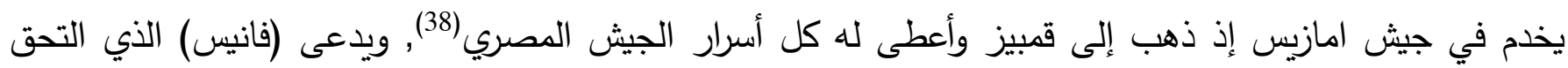

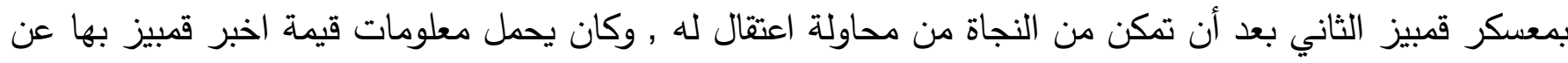

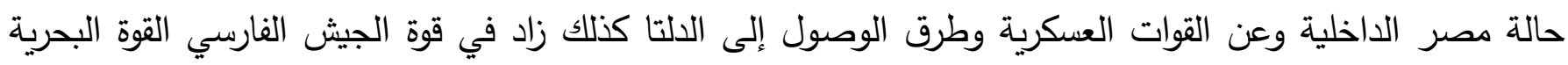

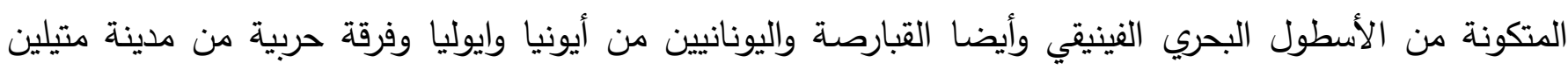

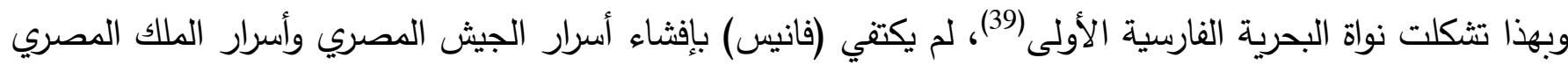

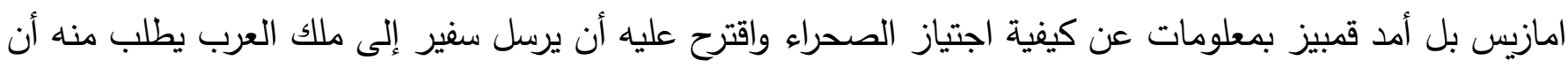

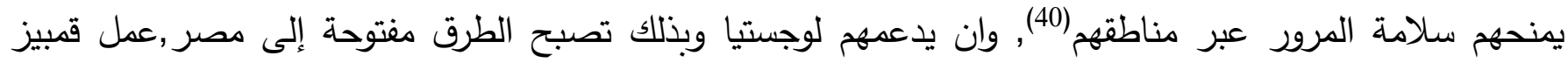
بنصيحة فانيس وأرسل إلى ملك العرب يطلب منه الماء والمساعدة فوافق ملك العرب وتبادل العهود (41) بينهما ، وابتكر لئر

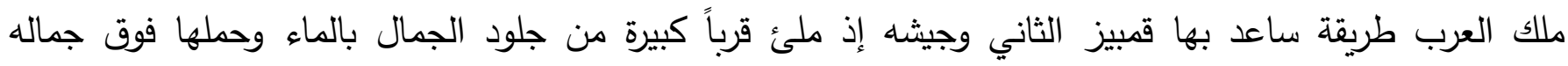

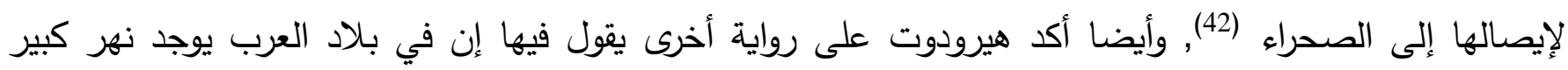

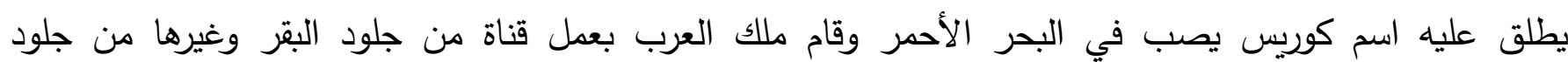
الحيوانات وخيطها بثكل طري ومدها من ذلك النهر إلى الصحراء القاحلة , وكان المسير لمدة 12 يوماً ونقلت بثلاث قنوات إلى ثلاثة أماكن على طول الطريق المؤدي إلى بلاد مصر . تعددت الآراء حول القبائل العربية التي ساعدت قمبيز الثاني في اجتياز الصحراء وكنلك من ملك العرب الذي

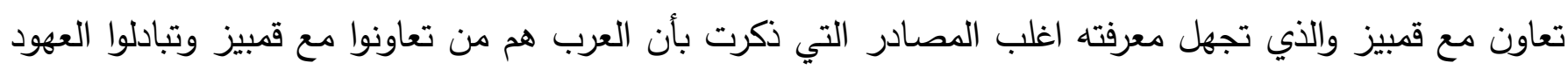

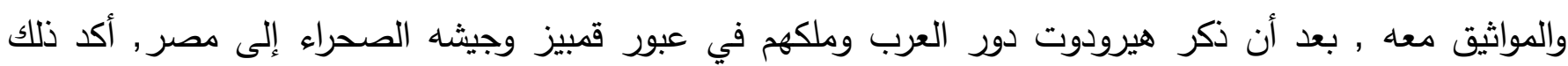

37 (المصدر نفسه ,ص134.

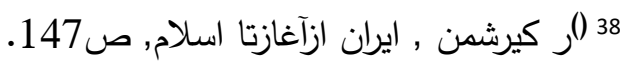

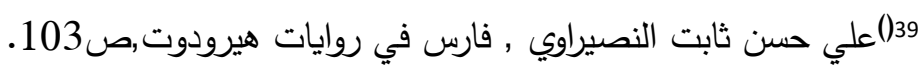

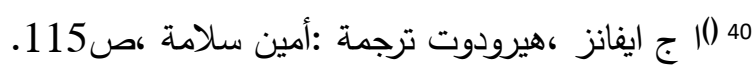

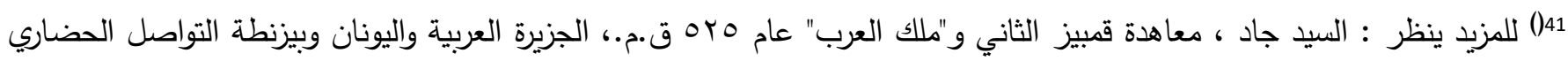

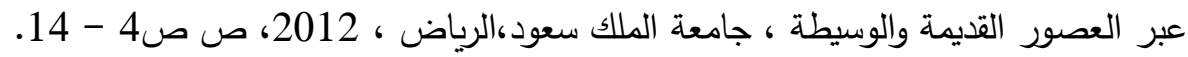

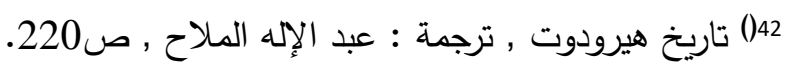

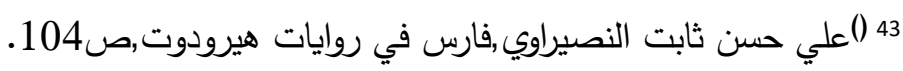


الأستاذ سليم حسن أن قمبيز حصل على مساعدة لوجستية من العرب والذين حددهم بالأنباط (44) , ومن نافلة القول إن

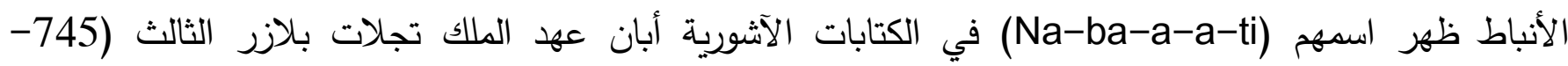

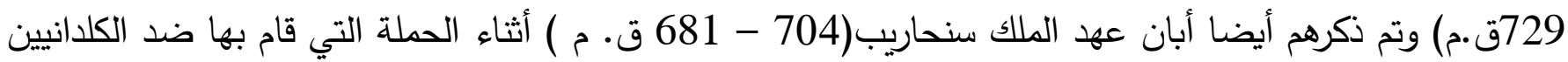
وقد ورد ذكرهم مرة أخرى في كتابات الملك اسرحدون(680-669 ق. م) و ويذكر هذا النقش بأنهم يسكنون شمال الجزيرة العربية ، وليس هؤلاء هم أنباط البتراء (45) ، كما إن الملك قمبيز سعى من من اجل مصات مصالحه الخاصة التي تهدف إلى تهئة الأمور السياسية وبالأخص كان هدفه احتلال مصر فلابد من استمالة شعوب المنطقة وكسب ودهم

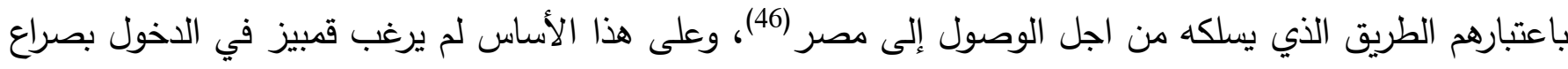

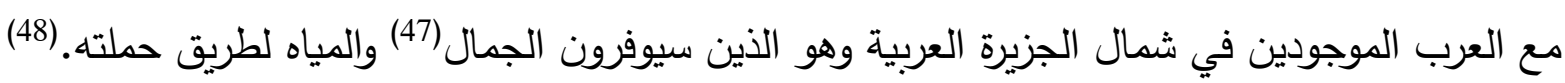
أن الرأي القائل بأن القبائل العربية التي ساعدت قمبيز الثاني في اجتيازه الصحراء هم الأنباط كان استتاده على التح موقع الأنباط إذ أن منطقتهم في فلسطين وشرق الأردن وهذا هو الطريق الذي يسلكه قمبيز خلال حملته على آلى الذيل

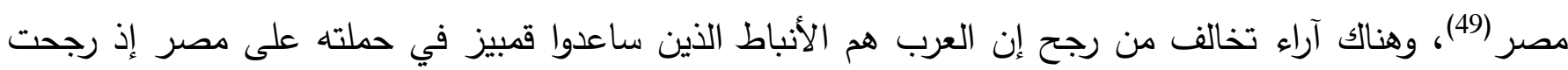
بعض الدصادر أن العرب الذين ساعدوه هم القيداريين وذلك لان القيداريين كان لهم دورا كبيرا في منطقة شمال الجزيرة

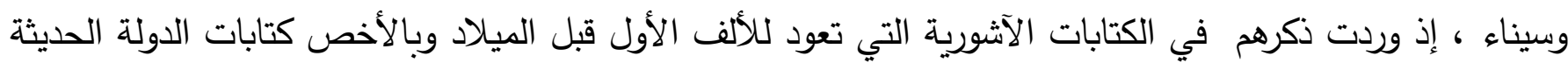

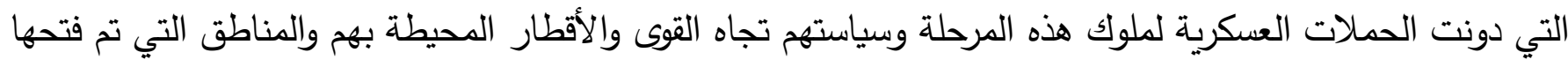
إذ كانوا يقومون بتعيين أمراء أو حكام أو ملوك محليين حكاما في دويلاتهم ويفرضون عليهم دفع الجزية وإبرام العهود والمواثيق وتقديم الولاء لهم فمنذ عهد الملك الآشوري شلهنصر الثالث (858-824 ق.م) والذي قام بست وعشئ وعشرين حملة عسكرية من اجل إخضاع الأقوام المنتشرة في أطراف الإمبراطورية الآشورية وذكر ذلك فئل في مدوناته وأخباره

$$
\text { (045 (مليم حسن,مصر القديمة,ج13,ص36. }
$$

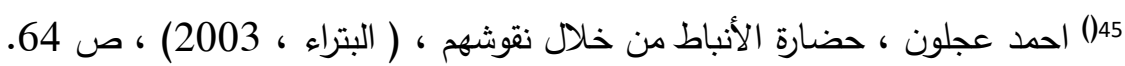
46 (اكاظم جبار سلمان ، الصلات السياسية بين العبرانيين والعراق القديم خلال الألف ، الألف الأول ق م ، رسالة ماجستير غير منشورة ، جامعة

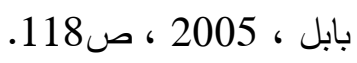
(047 عن الجمال في شبه الجزيرة العربية ينظر : RALPH W. BRAUER , THE CAMEL AND ITS ROLE IN SHAPING MIDEASTERN NOMAD SOCIETIES , Comparative Civilizations Review: Vol. 28 : No. 28 , Article 7,1993, pp.106-151.

: 48

Marwan G. Shuaib, The Arabs of North Arabia in later Pre-Islamic Times - Qedar, Nebaioth, and Others , Doctor of Philosophy in the Faculty of Humanities, The University of Manchester,2014.p.143.

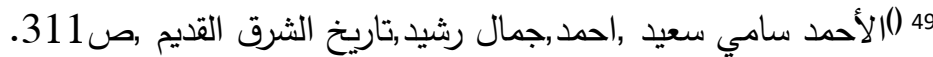


ونتيجة لهذه الحملات المتوالية وطد الآشوريين حكمه على معظم البلاد الواقع إلى الغرب من حدودهم واحكموا

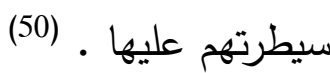

تسلم العرش بعد الملك شلمنصر الثالث الملك الآثوري تيجلات بيلازر الثالث (744-727 ق.م) وعندما تولى الحكم توجه إلى الحدود الثمالية أي حدود بلاد الأناضول والى الحدود الشرقية بلاد إيران فأدى هذا التوجه إلى اعتقاد

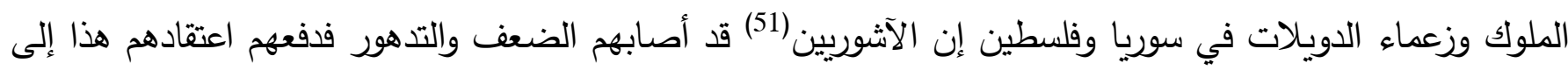

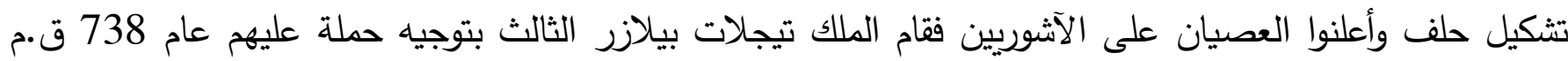

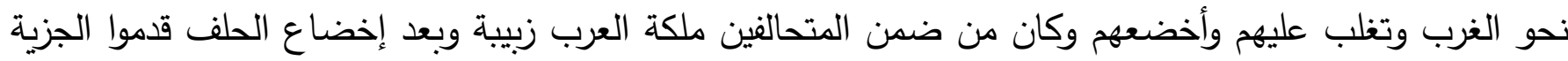

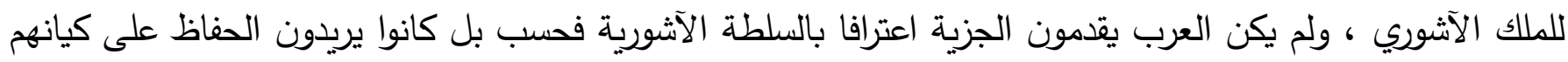

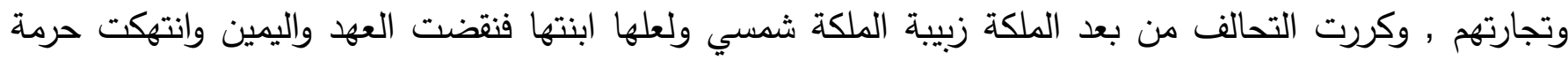

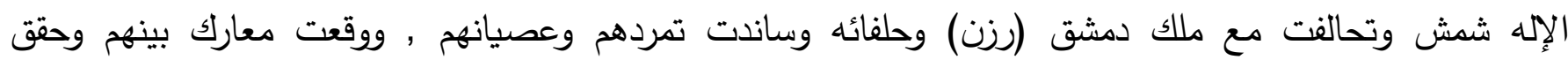

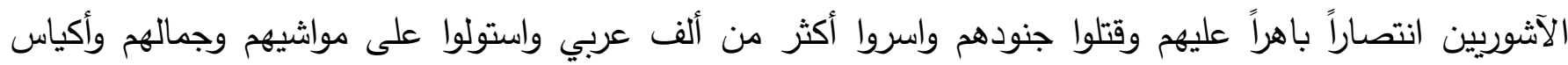
التوابل وتماثيل للآلهة العببية أما شمسي فهربت إلى الصحراء ولاحقوها فسلمت نفسها وعين الملك تيجلات بيلازر الثالث وصيا عليها للإشراف على إدارة مملكتها ومراقب لحركة التجارة ليضمن للخزينة الملكية الآثورية موارد مهمة

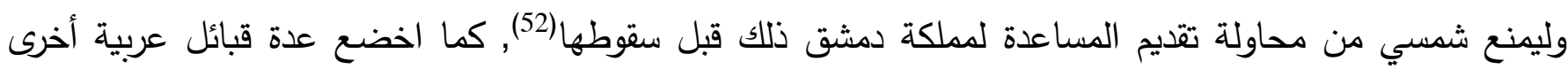
تقطن في المناطق المتاخمة لفلسطين إلى شرق وجنوبي وادي الأردن حتى مشارف حدود مصر , وبما أن العرب كانوا

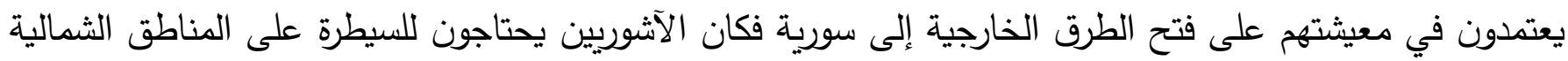

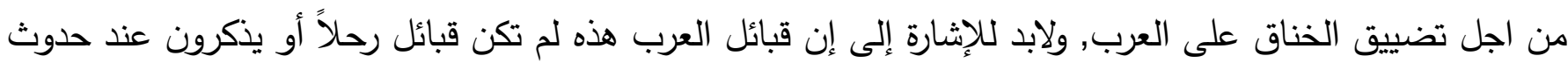

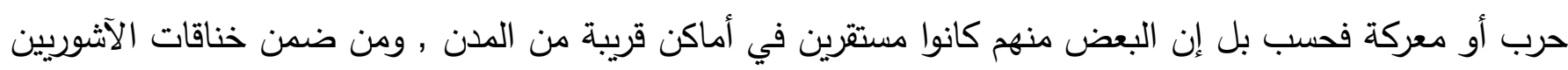

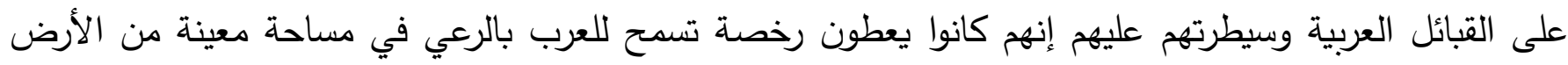
مقابل دفع ثمنا لإيجار الأرض كالرخصة التي أعطيت لرجل عربي اسمه (بد ئيل ـ بدعيل) (53), أو كانوا يسمحون للعرب بالرعي والزراعة في مناطق مجاورة للمدن مقابل قيامهم بحراسة المناطق وتأمين حمايتها وأمنها وفتح طريق الإريق

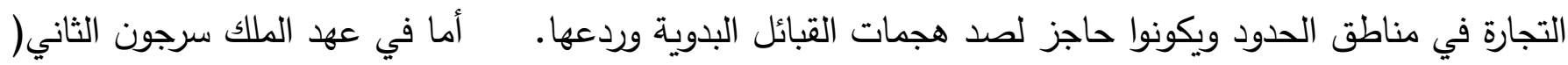
722-705 ق.م ) كانت سياسته تستتد على العلاقات السلمية بين آشور ومصر رونة وأسس مركز تجاري في ميناء يقع

$$
\begin{aligned}
& 50 \text { (المياء الكيلاني , سالم الآلوسي , أول العرب ... ,ص24,ص26. بالمك. }
\end{aligned}
$$

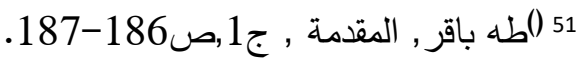

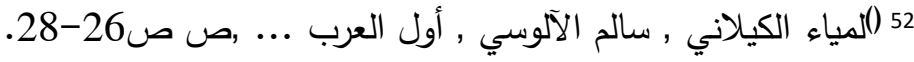

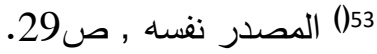


على مشارف مصر وليكون محل اختلاط المصرين بالآشورين , ويحتمل إن موقع هذا الميناء في منطقة العريش وعدت أبعد نقطة يصلونها الآشوريين في ذلك الوقت , وفي 715 ق.م قام سرجون بحملة على بعض القبائل العربية التي لم تقدم الجزيـة , إذ قام بترحيل جزء منهم إلى منطقة السامرة في فلسطين وان سياسة التهجير لم تكن جديدة إذ كانت متبعة من قبل الآشورين لتسهيل سيطرتهم على المناطق البعيدة , ولترحليهم إلى السامرة سبب آخر هو لتحويل تجارة البخور والتوابل نحو مدن فلسطين وسورية بدل أن تمر في الصحراء والصعوبات التي يلاقونها في سيطرة القبائل العربية ، ولهذا عمد سرجون بترحيل آخر وأسكنهم بالقرب من العريش وعين وصياً عربياً على المنطقة .(54) أما في عهد الملك الآشوري سنحاريب( 705 - 681 ق.م ) فكان عهده صفحة جديدة من تاريخ العرب إذ إن العرب أصبحوا سكان مستقرون يقنطون المناطق الغربية والجنوبية من بادية الثام , ووجدت قبائل عربية في الجنوب الشرقي من البادية تنتشر غرب بلاد بابل, وفي الحملة العسكرية التي قام بها الملك الآشوري سنحاريب على بابل ليقمع عصيان حاكم بابل مردوخ بلادان سنة 703 ق.م كان احد حلفاء بلادان شيخ عربي اسمه (بسقانو) و كان أخ الملكة

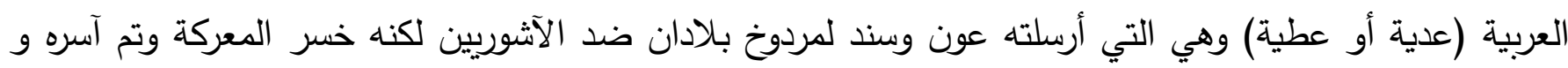
أخذه سنحاريب معه إلى نينوى و تعاون العرب مره أخرى مع أطراف و كيانات سياسية مناهضة للآشوريين و بذلك

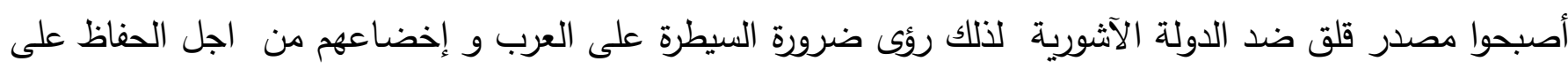
الطرق التجارية و قدمت بعض القبائل العربية الجزية و الهدايا الثمينة نتيجة الضغوط الآشورية (55)، قام سنحاريب بحملة حربية مرة أخرى إلى مناطق غرب بابل لإخضاع قبائل أدوم سنة 689 ق.م وكانت زعيمة المعارك ملكة عربية اسمها (تعل حونة) والتي عقدت حلف مع زعيم و ملك قبائل قيدار اسمه (خزعل), كانت قيدار من اكبر القبائل العربية و أقواها آنذاك و لعبت دور في سيد الأحداث و جاء أول ذكر لهم في عهد الملك تيجلات بيلازر الثالث , إذ وصلوا أوج قوتهم في عهد الملك الآشوري آشور بانيبال ، و تسلم العرش بعد سنحاريب ابنه (اسرحدون)681-669ق.م الذي اتبع سياسة الترضية نحو العرب , و زاره خزعل ملك القيداريين وجاءه محمل بالهدايا و الذهب و الأحجار الكريمة و قبل قدم الملك الآشوري اسرحدون من اجل إرجاع تماثيل الآلهة العربية التي أخذها منهم أبوه الملك سنحاريب بعد أن (56) انتصر على (تعل - حونة)

توسع القيدارين خلال القرن الثامن و السابع قبل الميلاد فانتشروا شرق بابل و استوطنوا (قدرينة ) مدينة محصنة تقع ضمن حدود (بيت داكوري) , وفي القرن السابع وصل امتداد سلطتهم إلى حدود الأردن و جنوب سورية , و

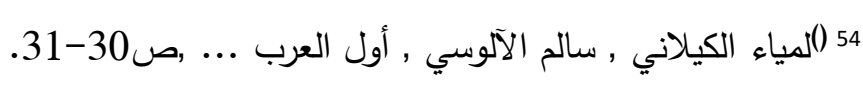

Reinhard Pirngruber, Arabs in late first millennium BC Babylonia, University : of Vienna, 2014,p.2. 
تاريخه يمتد إلى العهد البابلي الحديث وعهد الاخمينيين في القرن السادس والخامس ق.م وامتدوا نحو فلسطين حتى مشارف صحراء سيناء وان على الأغلب كانوا القيداريين يتألفون من مجموعة قبائل عربية كما جاء في مدونات الملك الآشوري آشور بانيبال"العرب وكل أمراء القيدار(57) "، أما عهد الملك الآشوري اسرحدون فقد شهد تعاون العرب القيداريين معه عندما أراد تحقيق طموحه في غزو مصر عام 675 ق.م , إذ كان أول ملك من آسيا يحاول غزوها ولتحقيق ذلك عليه أن يقطع صحراء سيناء فجمع من العرب الجمال وحملها بقرب الماء ـ (58) أما في عهد الملك الآثوري آشور بانيبال (686- 627 ق.م ) اسند العرب القيداريين المعارضة والمقاومة للنفوذ والسيطرة الآشورية خاصة عندما تنازع ( شمش شم - كن) حاكم بابل مع أخيه آشور بانيبال سنة650 ق.م وكان العرب يشكلون جبهة مهمة في الصراع , فقام ملك قيدار (يوطع الأول) و( امولادي ) زعيم قبيلة من قيدار بالهجوم على مستوطنات في غرب بادية الشام لتخفيف الضغط على بابل , لكن الملك آشور بانيبال أوقع بهم خسائر فادحة واسر امولادي مع جنوده كما اسر زوجة (يوطع الأول) فالتجأ يوطع إلى ملك النبط (نتن أو ناتنو) و لكنه خشي قوة الآشورين فأخضع قيدار وبعث الهدايا إلى آشور بانيبال وأيضا تجددت الحرب من قبل العرب ضد اشوربانيبال سنة 641-638 ق.م إذ هجم يوطع الثاني ملك قيدار والملك آبي يطع بمساعده من نتن ملك النبط وحققوا بعض النجاح بسبب انشغال آشور بحربها مع بلاد عيلام بعد ذلك قام الملك الآثوري بحملة كبيرة على القبائل العربية في الصحراء وهاجمهم , واستمر آشور بانيبال في ملاحقة القبائل العربية حتى قطع عنهم مصادر المياه ونقص طعامهم و دامت 3 شهور هذه الحملة في الصيف الحار دلالة على قوة المعارضة العربية وخطرها على الآشوريين ولأنهم في موسم صيف (59) ويحتاجون المياه اضطروا للخضوع وتقديم الجزية والهدايا

لابد لنا الآن إن نبين قضية مهمة جدا ، وهي إن القداريين وعلى الرغم من دورهم السياسي إلا إننا نجد لهم ذكر في المصادر الآشورية ، وهذا يدل لربما أنهم مروا بفترة ضعف بعد هذا الدور السياسي الذي ظهروا به أبان المرحلة (60). السابقة

بعد أن أتت قبيز الثاني استعدادات حملته في عام 525 ق.م سار عبر الصحراء للوصول إلى مصر لكن في هذه الأثناء وصله خبر موت الملك المصري امازيس وتسلم العرش من بعده ابنه بسماتك الثالث( 526-525 ق.م ) (61),

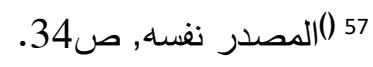
58 (اللمزيد عن حملة اسرحدون على مصر ينظر: أحمد حبيب سنيد الفتلاوي ، أسرحدون680 - 669 ق م، رسالة ماجستير عير

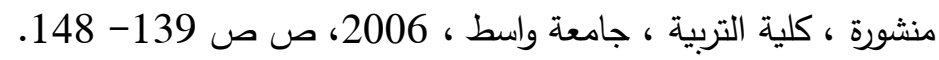

() Marwan G. Shuaib, The Arabs..., pp.124-125. 
عسكر جيوش قمبيز الثاني عند بلوزيوم (62) , كان الملك المصري بسماتك الثالث ينتظر قمبيز عند الفرع الثرقي لنهر النيل ومعه جيشه الذي يتكون من جنود مصريين وفرق عسكرية من الجنود المرتزقة الكاريين واليونانيين(63), والتقى الجيشان الاخميني والمصري في معركة شديدة قرب مدينة بلوزيوم هزم المصرين بها هزيمة كبيرة ، في حين حالف النصر قمبيز هذه المعركة وقد سانده أسطوله البحري الذي كان راسيا في عكا 525 ق.م (64). وهكذا انتهت الأسرة السادة والعشرين في بلوزيوم تلك الأسرة التي وحدت مصر وأصبحت مصر مره أخرى تحت سيطرة قوة أجنبية وهم

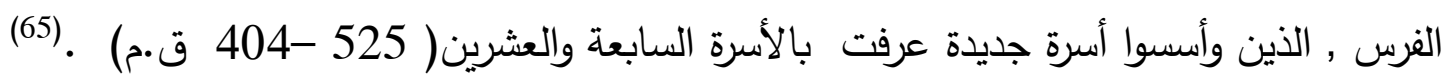

كما ورد ذكر مملكة أخرى في الكتابات المسمارية الآشورية أبان الألف الأول قبل الميلاد وهي ( د - د- ن) (- ) ديدان ) ، وقد احتلت عاصمة مملكة لحيان في شمال غرب الجزيرة العربية ، فكانت مركزا تجاريا مهمة مع شمال الجزيرة ومصر وبلاد الرافدين ، وقد ضمت تحالفات قبلية متعددة أهما ، ديدان ، معين ( التي تعرف بعلاقاتها مع مصر وعرفت ـ معين مصرن (66) ولحيان ،لهذا سيطرت على الطريق التجاري بين شمال الجزيرة مرورا بسيناء ثم مصر - والطريق الآخر بين بلاد الرافدين ومصر مرورا بشمال الجزيرة (67) ، ابرز ملوكهم في القرن الخامس هو (

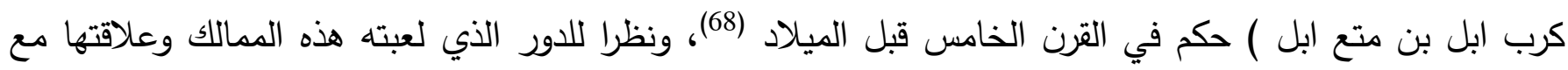
مصر ودورها في التجارة مع مصر وشمال الجزيرة ومعرفتها بالطرق البرية مع مصر ، اعتقد إن ملكها ( كرب ايل بن متع ايل ) هو الملك التعاون مع قمبيز وسهل له عملية الدخول إلى مصر ، ونحن لا نتقق مع هذا الرأي ، لوجود قوى مهيمنة على المنطقة ولها مراكز تجارية وحتى دينية في شمال مصر في سيناء ، وهم القيدارين •

ومن حيثيات المعارك التي دارت بين الآشورين والقبائل العربية أبا عهد الملك الآشوري شلمنصر الثالث إلى عهد الملك آثور بانيبال تثبت إن العرب الذين ساعدوا الملك الاخميني قمبيز الثاني في اجتيازه الصحراء من اجل الوصول إلى مصر هم العرب القيداريين وليس عرب الأنباط ، أو معين مصرن أو الديدان - فقد بينت الحروب التي خاضتها

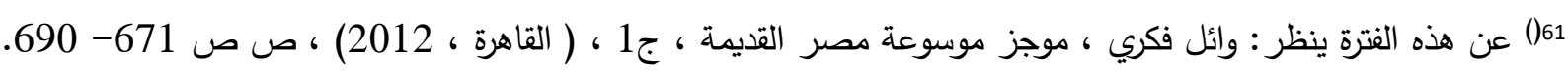

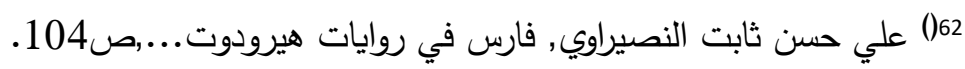

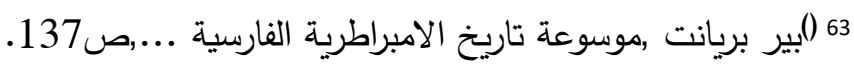

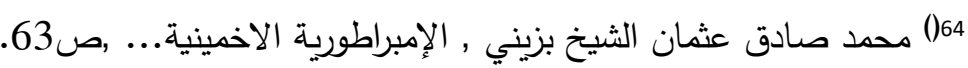
65 (ارضان السيد ، تاريخ مصر القديمة ، ج2 ، من بداية الأسرة الخامسة عشر حتى دخول الاسكندر الأكبر مصر 332ق .م ، هيئة

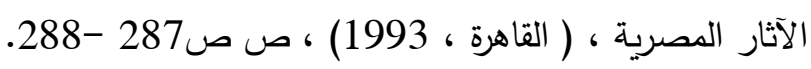

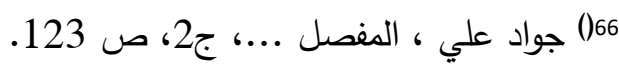
ه7(63) للمزيد ينظر : عمر فيصل سليم احمد الخولي ، مملكة لحيان ـ دراسة في الأحوال الاجتماعية والدينية والاقتصادية ، رسالة

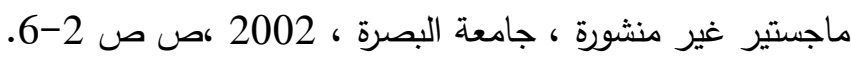
68 (1) جواد علي ، المفصل في تاريخ العرب قبل الإسلام ، ط2 ، ( بغداد ، 1993 ) ) ، ج2 ، ص243. 


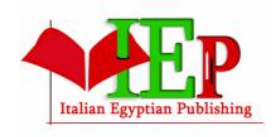

ISSN: 2735-4393
INTERNATIONAL JOURNAL OF

CREATIVITY AND INNOVATION IN HUMANITIES AND

EDUCATION

VOLUME 4, ISSUE 1, 2021, $24-47$.

$\overline{\vdots: \vdots\left(\begin{array}{c}\text { ISTITUTO } \\ \text { italiano } \\ \text { DI CULTURA }\end{array}\right.}$

www.egyptfuture.org/ojs/

قيدار وسياستها مع الآشوريين قوتها وقدرتها وبروزها من بين كل القبائل العربية التي تواجدت آنذاك في شمال الجزيرة

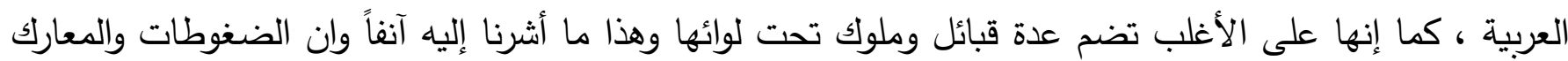
التي تعرضت لها القبائل العربية وخصوصا معاركهم مع الآشوريين أدى إلى تحالفهم مع قمبيز الاخميني ومساعدته في اجتياز صحراء سيناء , وان ماذكرته هند التركي بخصوص العلاقة بين القيداريين والاخمينيين جعلهم يتمتعون

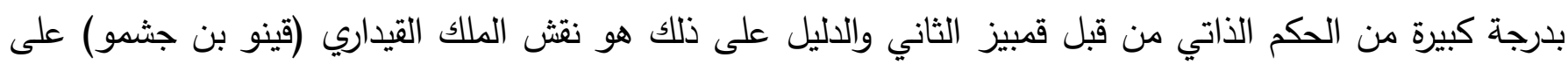

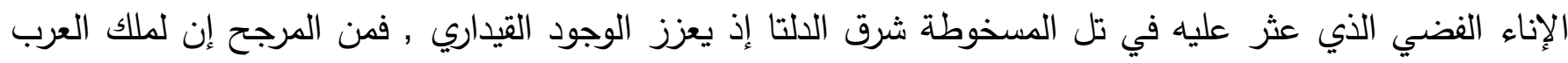

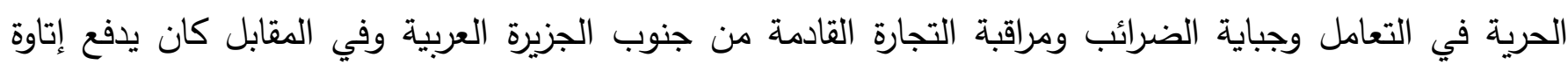

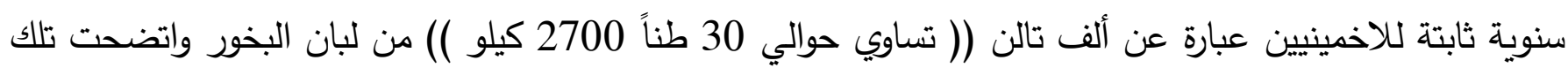

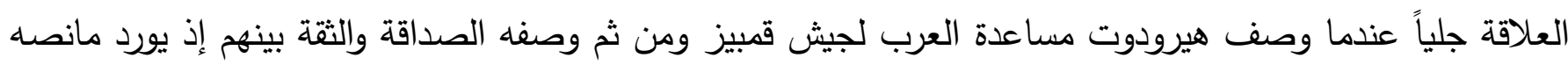

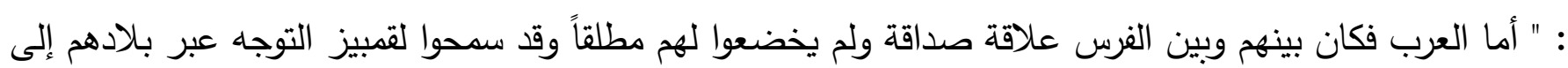
مصر وبدون مساعدتهم لم يكن بمقدور الفرس الوصول إلى مصر" كما إن تعاظم قوة القيداريين خلال الفترة الاخمينية

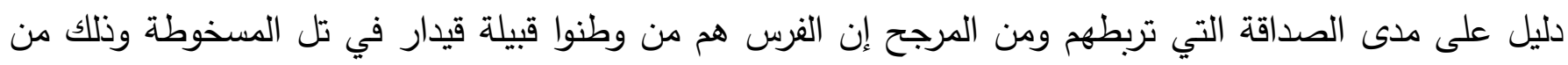

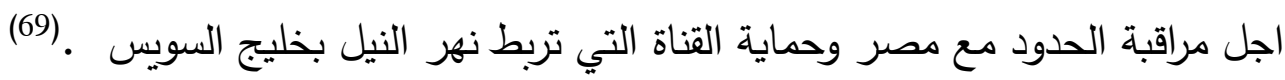
وان ما ذكرته هند التركي حول اسم ملك العرب يتضارب مع رأي هتون الفاسي عندما حددت ملك العرب الذي

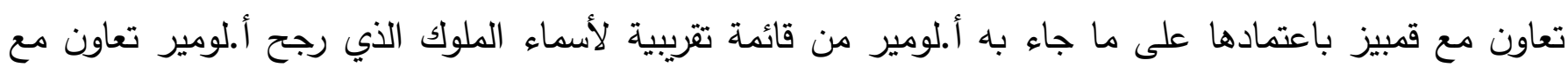

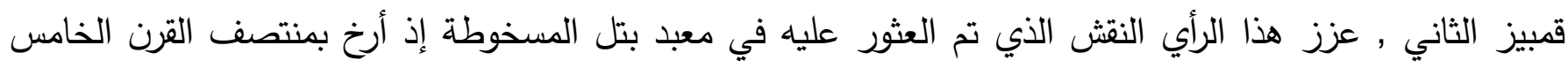
ق.م وورد ذكر قيدار في المصادر الاخمينية باسم ( قي ـ ذا ـ ري ) ) , وان ملك العرب الذي قيل النيل انه ساعد قمبيز

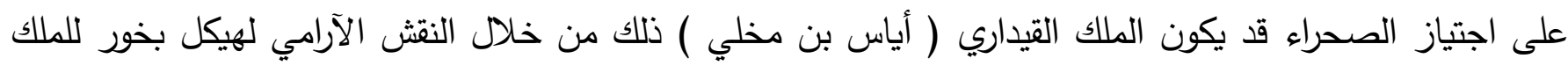

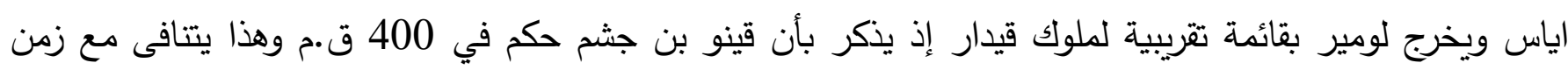

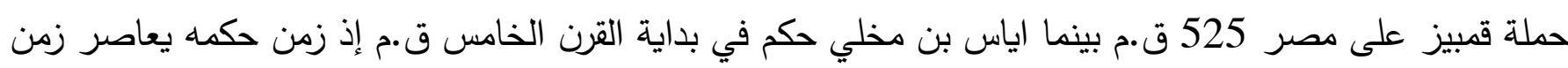

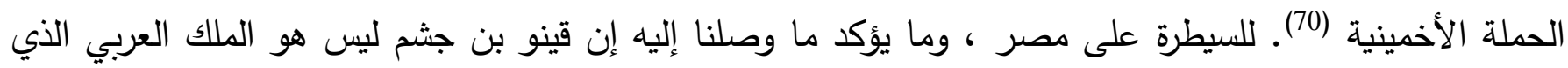

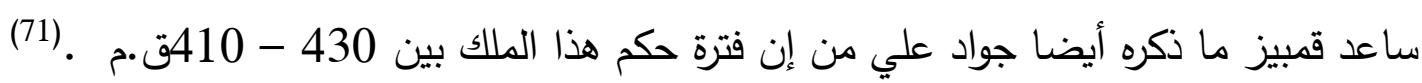

()69) هند بنت محمد التركي , مملكة قيدار , ص115. 70 ()هتون أجواد الفاسي , الحياة الاجتماعية في شمال غرب الجزيرة العربية في الفترة مابين القرن السادس قبل الميلاد والقرن الثاني

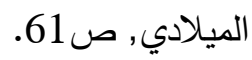

71 ()جواد علي ، المفصل ...، ج2، ص 23. 
يستتنج الباحثان احتمالان مهما عن سير خط الحملة العسكرية الاخمينية على مصر وهما .

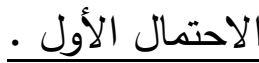

بابل و منه الى ادوماتو و منها سلك وادي السرحان وصولا الى مناطق عمون السير باتجاه الغرب و بعد ذلك النزول جنوبا الى سيناء و استمرار الوصول الى منئ وفيس.

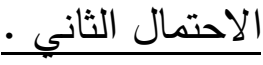

بابل و منه الى ادوماتو و منها الى تيماء فمعان و الدخول الى سيناء ليستمر قمبيز وصلًا الى مدفيس.

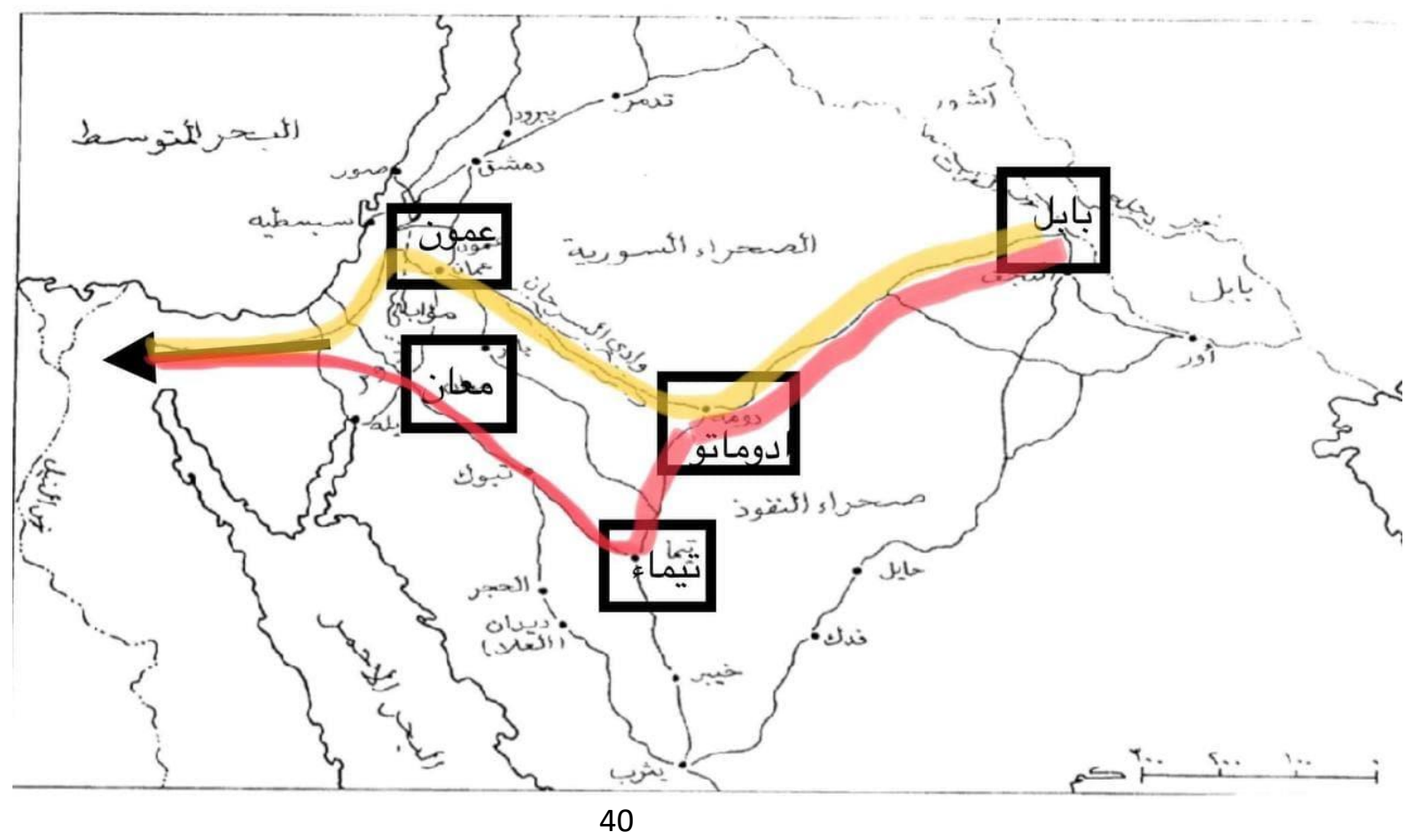


الملاحظ إن كلا الاحتمالين وارد في سير جيوش قمبيز نحو مصر و قد يكون خط تيماء اقصر مسافة للوصول الى في سيناء ، فيما عدا نقطة واحده بان هذه الجيوش عليه قطع مرتفعات العقبة و هي مناطق عالية مقارنة بمنطقة عمون

$$
\text { والتي تعتبر مرتفعات أيضا . }
$$

إن مسألة الميل الى الاحتمال الثاني و هو خط تيماء معان قد يكون بسبب وجود حاضرة المعلم و الذين من الممكن تقديم المساعدة لهذه الجيوش و العبور الى سيناء بطرق مختصرة و مسالة اقل من طريق عمون . في حين يكون في الاحتمال الأول إن هذه الجيوش بعد الوصول الى عمون فإنها من المكن أن تعبر عدة حواضر

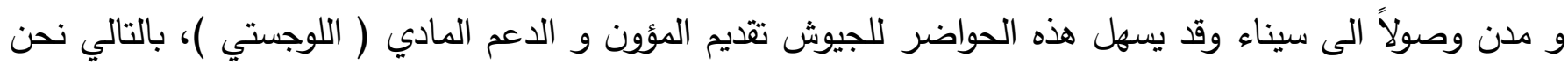

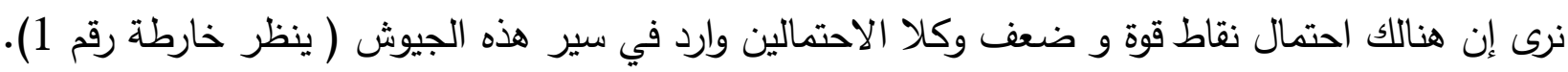

\section{أسباب نجاح حملة قمبيز على مصر .}

1- كانت مصر قد فقدت آخر فراعنتها ــ أحمس الثاني ذا الثخصية ذات الوزن والسمعة القيمة في العالم القديم ، وقد خلفه ابنه بسماتك الثالث الذي كان بعيدا عن شئون الحكم طوال أيام أبيه فضلا عن انه لم يكن قد تمرس في من شئون الحرب والقتال وإنقاذ مصر ولو بالطرق السياسية كالمفاوضات أو عقد التحالفات أو حتى تحصين البلاد بطريقة مكثفة في الأماكن الضعيفة في حدود مصر ، وكان لهذا أثرا بجعل مصر فريسة سهلة للإمبراطورية الاخمينية التي ظهرت كقوة جديدة على الساحة السياسية الدولية في الشرق الأدنى القديم •

2- سياسة التسامح الاخميني مع اليهود في بابل ساهم في دخول الملك قمبيز الثاني الى مصر فكانت الجالية اليهودية في مصر سندا قويا للاخمينيين ، كما كانوا من قبل عند سقوط بابل عندما ساعدوا كورش الثاني في احتلالها

3- تخلي اليهود عن موقفهم الداعم لمصر ووقوفهم مع قمبيز ، عدت من الأسباب التي ساهمت بشكل مهم على تقوية حملته البرية على مصر فقد صرح وسهل لليهود ببناء معبد في القدس ، فضمن بذلك وجود قاعدة قوية ينقض منها على الحدود المصرية ، فضلا على انه كسب ولاء الجنود اليهود المرتزقة الذين كانوا في خذمة فرعون مصر • امازيس 
4- إن حالة البلاد الداخلية وما تفشى فيها من ثورات وانثقاقات بين أفراد الشعب من جهة وما حدث فيها من انقسام في الجيش من جهة أخرى في بداية حكم أحمس الثاني قد أنهاك قواها وبث فيها روح الفوضى ، وهذه الفوضى عمت البلاد منذ عام 569 ق. م واستمرت حتى عام 525 ق م .

5- إضعاف حلفاء الفراعنة بعد انتهاء الحرب البابلية المصرية بهزيمة البابليين على يد الفراعنة بسبب أخطاء وأطماع نبوخذ نصر وسياسته العدائية مع حلفائه، فبعد أن استقرت الأمور في بابل قام أحمس الثاني بعقد تحالف مع لئه العاهل البابلي نبونائيد إلا إن الملك الاخميني كور وابنه قمبيز تمكنوا بشق الأنفس وبصعوبة شديدة من السيطرة

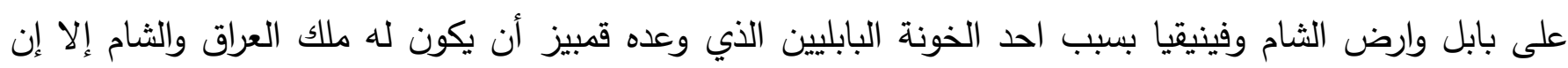
قمبيز قتله فيما بعد ، وفرض نفوذه على تلك المناطق ففي عام 553 ق.م سقط استاجز ملك ليديا في قبضة الاخمينية وخضعت القلاع الميتانية (السورية ) واستسلم الفينيقيين وسقطت آسيا الصغرى سواء بقوة السلاح أو بالاستسلام مما دفع فرعون مصر أحمس الثاني تفاديا لهذا الخطر بان يعقد تحالفات جديدة مع كرويسوس ملك ليديا وبيلوكتراس حاكم ساموس واتفاقية دفاع مشترك مع أثينا وذلك في عام 546 ق.م إلا إن ليديا وساموس سقطوا في قبضة كوش ترش الاخميني بسبب استعجالهما في هجوم غير ناجح فلم يتبقى سوى الإغريق حلفاء للفراعنة .

6- عندما تسلم الحكم أحمس الثاني تغيرت السياسة المصرية إذ انتهجت سياسة جديدة تجاه الثرق والغرب ونلاحظ ذلك من خلال حالة السلام بين هذا الملك وبين خلفاء الملك البابلي نبوخذ نصر الثاني ، قامت علاقات طيبة بين المملكتين ولاسيما في الأيام الأخيرة من عهد الدولة البابلية وخاصة في عهد الملك البابلي نبونائيد .

7- سياسة الفرعون امازيس للحد من سلطة الكهنة ، ومكافحة الكهنوتية وَلد الكثير من الاستياء تجاهه من قبل رجال

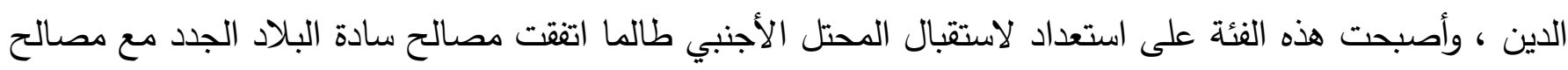
الفئات الميسورة في المجتمع المصري ، وخصوصا كهنة مدينة سايس ( صا الحجر ) .

8- بتولي أحمس الثاني عرش مصر تغيرت الأسرة الحاكمة ، وذلك لأنه لم يتمتع بالام الملكي ويعد هذا اغتصبا للعرش ، لكنه كان يتمتع بتأييد الرأي العام المناهض للأجانب ، وعلى الرغم من إن المصريين اظهروا له الكره في بادئ الأمر ولم يشعروا من ناحيته باحترام كبير لأنه كان فيما مضى شخصا عاديا ولم يكن من أسرة ملكية أو ارستقراطية وان حالة امازيس تعد أمر شاذا قد نال الملك اغتصابا ومن ثم أراد أن يقنع الثعب بطريقة أخرى في أحقيته 
8- اعتماد الجيش المصري على غالبية كبيرة من المرتزقة اليونان إن العلاقات بين مصر وبلاد الإغريق ترجع إلى أقدم الحقب التاريخية فقد كثفت الحفائر في جزيرتي كريت وساموس عن آثار مصرية تثبت وجود علاقات بين مصر وهذه الجزيرة منذ عصر ما قبل الأسرات وان التقارب بيزهما بلغ ذروته في عصر الدولة الحديثة وتؤيد هذه الآثار نقوش مصر القديمة التي تمثل وفدا من أهل كريت يقدمون لتحوتمس الثالث أواني فضية وسبائك من البرونز لعلها هدايا للملك المصري من اجل تحسين العلاقات والسماح لهم بالتبادل التجاري مع مصر . وكان لظهور بسماتك الأول مؤسس الأسرة السادسة والعشرين (663 -619 ق م ) اثر بالغ الأهمية حيث تمكن من تطهير الدلتا من الآشوريين وقام بتوحيد مصر تحت رايته متخذا من مدينة سايس عاصمة له وسار بسماتك نحو التقدم والرخاء فقد استمر في أحياء مجد البلاد القديم والرجوع الى ما كان للصر من علوم وفنون وثقافة حتى رد لها شي من مكانتها القديمة .

1. إن الصراعات النفسية التي عاشها قمبيز الثاني بسبب خوفه من أخذ كرسي العرش منه أو الانقلاب عليه

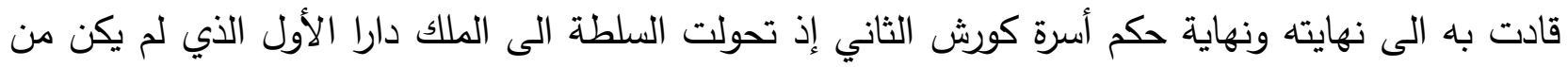

$$
\text { سلالة كورش. }
$$

2. كان أكبر انجاز عسكري للملك قمبيز الثاني هو تأسيس القوة البحرية الأخمينية . 3. إن الملك قمبيز الثاني شخصية عسكرية تشبه شخصية أبيه كور انس وكان طموحه خلال فترة حكمه هو السعي

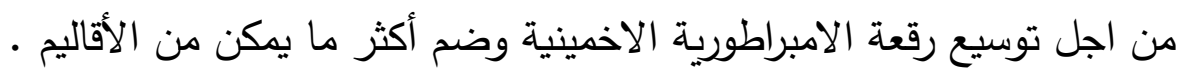

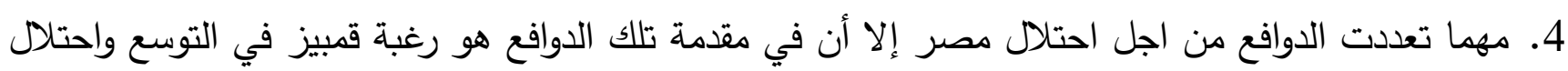

5. ابرز حدث في حياة قمبيز الثاني هو احتلاله لهصر سنة 525 ق.م وتأسيس سلالة حاكمة جديدة في مصر .

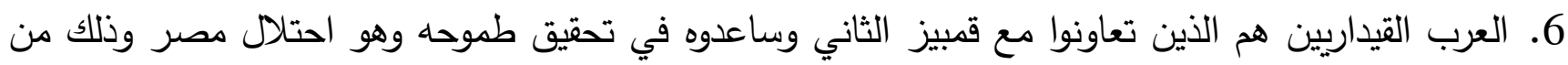

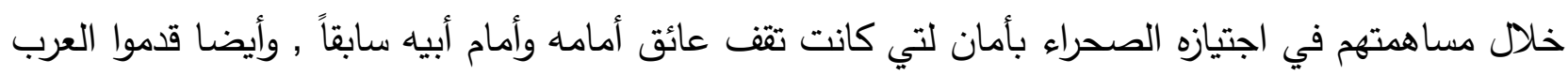

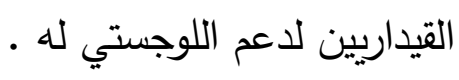


7 ـ إن ملك العرب الذي تبادل عهود الصداقة والمواثيق مع الفرس هو الملك القيداري اياس بن مخلي الذي حكم في القرن الخامس قبل الميلاد والذي يعاصر زمن حكمه الحملة الأخمينية على مصر الهر 525 ق.م .

Olmsted ,history of the Persian empire,Chicago.1984.

R.J. van der Spek, Cyrus the Great, Exiles and Foreign Gods - A . Comparison of Assyrian and Persian Policies on Subject Nations , "Cyrus de Pers in Assyrisch perspectief: Een vergelijking tussen de Assyrische en Perzische politiek ten opzichte van onderworpen volken, ( VU University Amsterdam , 1993). RALPH W. BRAUER, THE CAMEL AND ITS ROLE IN SHAPING MIDEASTERN NOMAD SOCIETIES, Comparative Civilizations Review: Vol. $28:$ No. 28 , Article 7,1993. arwan G. Shuaib, The Arabs of North Arabia in later Pre-Islamic Times - Qedar, Nebaioth, and Others, Doctor of Philosophy in the Faculty of Humanities, The University of Manchester, 2014. Reinhard Pirngruber, Arabs in late first millennium BC Babylonia, University of Vienna, 2014.

1. احسان بار شاطر , داستانخاي ايران باستان,شركة انتشارات علمي,وفرهتك,(تهران،1393 ش) .

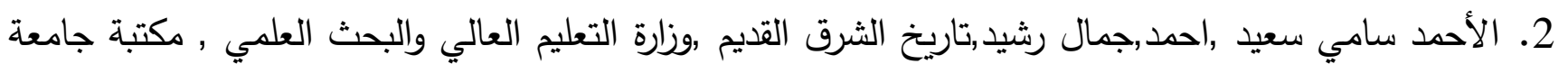
بغداد,1988.

3. أحمد حبيب سنيد الفتلاوي ، أسرحدون680 - 669 ق م، رسالة ماجستير عير منشورة ، كلية التربية ، جامعة واسط ، 2006. 
4. احمد عجلون ، حضارة الأنباط من خلال نقوشه ، ( البتراء ، 2003).

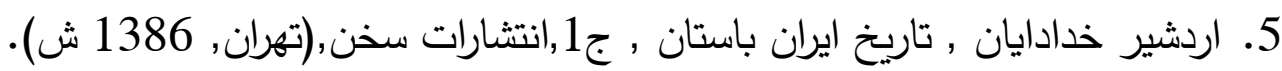

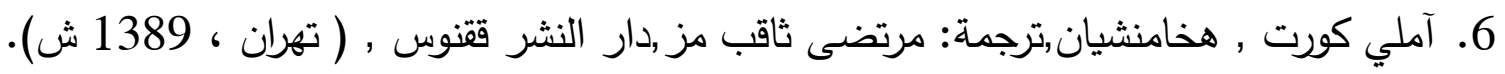

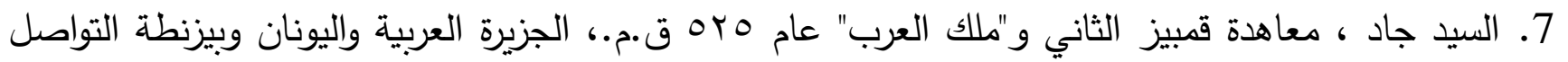

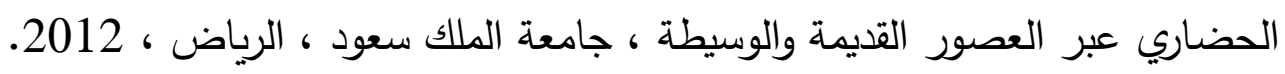

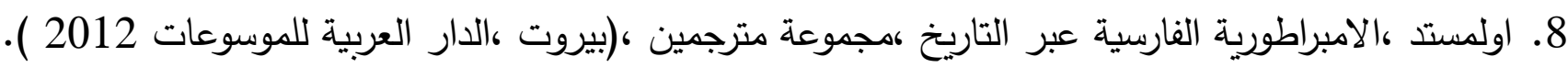

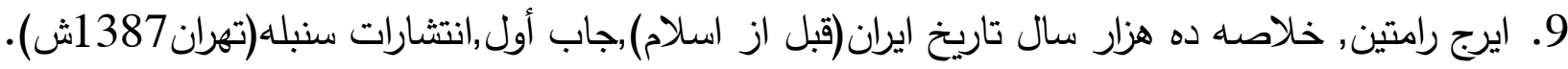
10. ايمان لفته حسين, الدين والسياسة في الدولة الأخمينية (558-330ق.م,أطروحة دكتوراه,غير منشورة,جامعة واسط ركلية التربية ,2012م.

11. بير بريانت , موسوعة تاريخ الامبراطرية الفارسية من قورش الى الاسكندر ,بيروت,الدار العربية

$$
\text { للموسوعات,2012م. }
$$

12. تاريخ هيرودوت ,ترجمة: عبد الإله الملاح ,مراجعة: احمد السقاف وحمد بن صراي,أبو ظبي , المجمع الثقافي , 2001م.

13. جواد علي ، المفصل في تاريخ العرب قبل الإسلام ، ط2 ، ( بغداد ، 1993 ). 14. جورج رو , العراق القديم ,ترجمة: حسين علوان حسين , (بغداد,ب.ت).

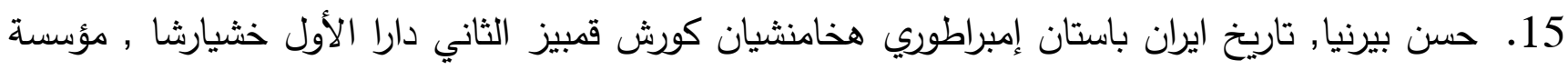

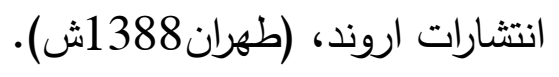

16. ر كيرشمن , ايران ازآغازتا إسلام, ترجمة:محمد معين ، ( تهران ، 1394ش).

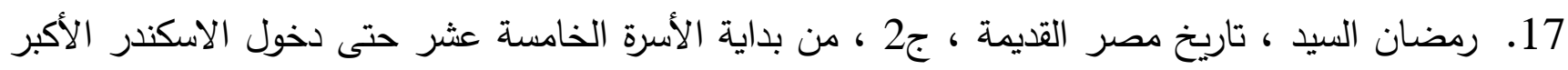

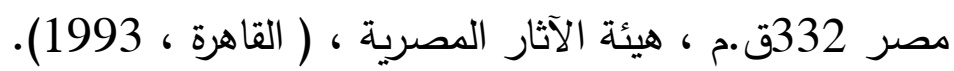
18. سليم حسن,مصر القديمة,ج13,1القاهرة, 2001). 19. شيرين بياني , تاريخ ايران باستان , ج2,ازوروداريايهابه ايران نابانهامنشيان,دانشكاه سمت مركز تحقيق

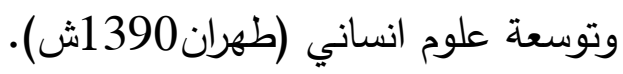

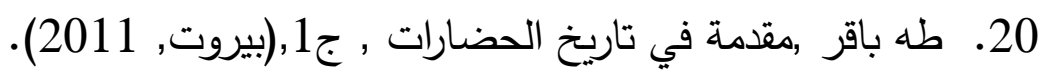
21.طه باقر ,مقدمة في تاريخ الحضارات , ج2, بغداد,1956م. 22. طه باقر وآخرون , تاريخ ايران القديم ,مطبعة جامعة بغداد, (بغداد , 1979م). 
23. علي حسن ثابت النصيراوي,فارس في روايات هيرودوت , أطروحة دكتوراه غير منشورة,جامعة بغداد,كلية

$$
\text { الآداب,2015م. }
$$

24. علي علكم خريبط الدريعي , المؤسسة العسكرية الأخمينية (559-330ق.م)رسالة ماجستير غير منشورة , جامعة واسط ,كلية التربية,2015م.

25. عمر فيصل سليم احمد الخولي ، مملكة لحيان ـ دراسة في الأحوال الاجتماعية والدينية والاقتصادية ، رسالة ماجستير غير منشورة ، جامعة البصرة ، 2002.

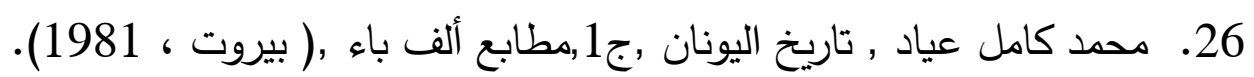

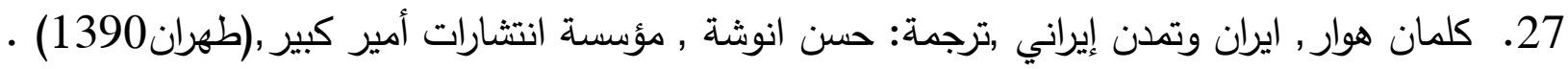
28. كاظم جبار سلمان ، الصلات السياسية بين العبرانيين والعراق القديم خلال الألف الأول ق م ، رسالة

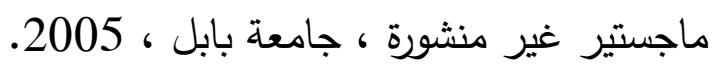

29. لمياء الكيلاني , سالم الآلوسي ,أول العرب من القرن التاسع وحتى السادس قبل الميلاد ,المؤسسة العربية للدراسات والنشر الندن,2012م.

30. محمد صادق عثمان الثيخ بزيني , الامبراطورية الاخمينية 559-331ق.م, رسالة ماجستير ,جامعة الدول

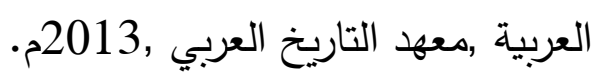

31. محد صقر خفاجة , هيرودوت يتحدث عن مصر ,القاهرة,ب.ت.

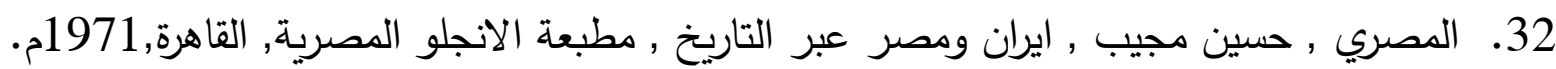

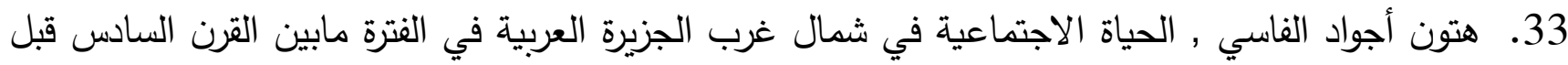

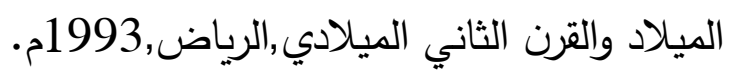
34. هند بنت محمد التركي , مملكة قيدار , مكتبة الملك فهد الوطنية, الرياض,2011م. 35. : وائل فكري ، موجز موسوعة مصر القديمة ، ج1 ، ( القاهرة ، 2012). 
